Review

\title{
Tau Protein Modifications and Interactions: Their Role in Function and Dysfunction
}

\author{
Anna Mietelska-Porowska, Urszula Wasik, Marcelina Goras, Anna Filipek and \\ Grazyna Niewiadomska *
}

Nencki Institute of Experimental Biology, Polish Academy of Science, 3 Pasteur Street, Warsaw 02-093, Poland; E-Mails: a.mietelska@nencki.gov.pl (A.M.-P.); uwasik@nencki.gov.pl (U.W.); m.goras@nencki.gov.pl (M.G.); a.filipek@nencki.gov.pl (A.F.)

* Author to whom correspondence should be addressed; E-Mail: g.niewiadomska@nencki.gov.pl; Tel.: +48-22-589-2409, Fax: +48-22-822-5342.

Received: 29 November 2013; in revised form: 11 February 2014 / Accepted: 4 March 2014 / Published: 18 March 2014

\begin{abstract}
Tau protein is abundant in the central nervous system and involved in microtubule assembly and stabilization. It is predominantly associated with axonal microtubules and present at lower level in dendrites where it is engaged in signaling functions. Post-translational modifications of tau and its interaction with several proteins play an important regulatory role in the physiology of tau. As a consequence of abnormal modifications and expression, tau is redistributed from neuronal processes to the soma and forms toxic oligomers or aggregated deposits. The accumulation of tau protein is increasingly recognized as the neuropathological hallmark of a number of dementia disorders known as tauopathies. Dysfunction of tau protein may contribute to collapse of cytoskeleton, thereby causing improper anterograde and retrograde movement of motor proteins and their cargos on microtubules. These disturbances in intraneuronal signaling may compromise synaptic transmission as well as trophic support mechanisms in neurons.
\end{abstract}

Keywords: tau protein; cytoskeleton; microtubule; tau kinases and phosphatases; tau interacting proteins; neurodegenerative disorders; neurotrophic support 


\section{Introduction}

Tau protein belongs to the family of natively unfolded microtubule-associated proteins that binds to microtubules, is involved in their assembly and stabilization [1] and in regulation of the motor-driven axonal transport. Earlier work showed that tau is concentrated predominantly in neuronal axons [2,3]. However, recent data suggest that tau also might play a physiological role in dendrites [4-6]. Six tau isoforms, produced by alternative mRNA splicing of the MAPT gene located on chromosome 17q21.31, are expressed in the adult human brain [7]. Each isoform contains either 3 (3R) or $4(4 \mathrm{R})$ repeat domains responsible for the interaction with microtubules. In the cerebral cortex of healthy adults the amounts of $3 R$ and $4 R$ tau are equal [8]. It has been also found that the expression of tau is roughly two-times higher in grey matter of the neocortex when compared to white matter or to the cerebellum [9].

Tau function depends on its phosphorylation state [10,11]. The incorporation of phosphate groups into tau depends on its conformation and on the balance between the activities of tau kinases and phosphatases. Changes in tau conformation could result in increased phosphorylation and in decreased binding to microtubules which is important in tau-mediated neurodegeneration [12]. Excessively phosphorylated tau accumulates in the somatodendritic compartment of neurons, aggregates and eventually forms neurofibrillary tangles (NFTs) [13]. There is an evidence that soluble overly phosphorylated tau contributes to neuronal dysfunction before its deposition [14]. It has been shown that highly phosphorylated tau interferes with neuronal functions, such as mitochondrial respiration and axonal transport $[15,16]$. Biochemical and immunostaining data indicate that overphosphorylated, aggregated tau makes up the intracellular filamentous inclusions present in many human neurodegenerative diseases collectively named tauopathies.

Tau excessive phosphorylation and aggregation could be driven by its interaction with several other proteins like $\beta$-amyloid, Fyn kinase, Pin1, heat shock cognate Hsc70 and heat shock protein Hsp90, immunophilins FKBP51 and FKBP52, $\alpha$-synuklein or actin interacting protein PACSIN1. As the consequence of these interactions tau accumulates in dendritic spines, where it suppresses synaptic responses [17,18]. In neurons excessively phosphorylated tau is involved in: microtubule destabilization, impaired axonal transport of substances [19], post-synaptic dysfunction, compromised cell signaling and, as consequence, cognitive impairments ensue [20].

\section{Tau Protein}

Tau protein is widely expressed in the central and peripheral nervous system, but is also present in kidney, lung and testis [21]. Although tau is most abundant in axons [22-25], it is also found in somatodendritic compartments [26] and in oligodendrocytes [27].

Biophysical studies revealed that tau has hydrophilic properties and the protein exists normally as a natively unfolded or intrinsically disordered protein $[28,29]$. The polypeptide chain of tau is highly flexible and mobile and has only a low content of secondary structures ( $\alpha$-helix, $\beta$-strand, poly-proline II helix). Primary sequence analysis demonstrates that the tau molecule contains three major domains, defined on the basis of their microtubule interactions and/or their amino acid character: an acidic $N$-terminal part; a proline-rich region and a basic $C$-terminal domain. Thus, tau protein is a dipole with 
two domains having the opposite charge [30]. This asymmetry of charges is crucial for interactions between tau and microtubules and other partners as well as for internal folding and aggregation [31].

The $C$-terminal domain binds to microtubules and promotes their assembly and is termed the "assembly domain" [32]. Binding to microtubules occurs through repeated domains (R1-R4) encoded by exons 9-12. Each repeat consists of highly conserved stretches of 18 residues. The repeats are separated from each other by 13- or 14-residue spacer regions [33]. Many studies support a role for the assembly domain in the modulation of the phosphorylation state of tau protein. A direct and competitive binding has been demonstrated between the region of tau containing residues 244-236 (numbering of amino acids is that of the longest human tau) and the microtubule or protein phosphatase 2A (PP2A). As a consequence, microtubules could inhibit PP2A activity by competing for binding to tau [34].

The middle region of tau residues 150-240 contains numerous prolines, which are targets of many proline-directed kinases and binding sites for proteins with SH3 domains. This part of the tau molecule is termed as a "proline-rich domain" [31].

The acidic $N$-terminal part of tau does not bind to microtubules but projects away from the microtubule surface and is termed "projection domain" [35]. This domain of tau may interact with other cytoskeletal elements, mitochondria or neuronal plasma membrane [36-38] and it may determine spacing between microtubules in the axon [39]. In peripheral neurons tau contains an additional $N$-terminal sequence encoded by exon $4 \mathrm{~A}$ which generates a specific peripheral neuron isoform called "big tau" [40].

\section{Role of Tau Protein in Neurons}

The tau is a multifunctional protein [41-43] (Figure 1). It has numerous binding partners, including signaling molecules, cytoskeletal elements and lipids. The most important function of tau is its role in tubulin polymerization. On tubulin, the tau interacting site is located at the $C$-terminal end, which is highly acidic. Binding of tau to tubulin is regulated by post-translational modifications, especially by phosphorylation. Phosphorylation may neutralize the positive charge [44], alter the conformation and detach tau from microtubules [45]. In pathological conditions, tau self-polymerization and aggregation might also affect the tau-tubulin binding [46]. Tau may interact with microtubules directly and indirectly. Direct interactions include the binding, stabilization and promotion of microtubule assembly [47]. The ability of tau to bind microtubules depends on the microtubule-binding domain and on adjacent regions [48]. Indirect interaction of tau with microtubules affects other proteins that may or may not interact with microtubules by themselves. These interactions may require the projection domain of tau [31,49]. 
Figure 1. Tau is a multi-functional protein. As a microtubule-associated protein tau contributes to microtubule dynamics and participates in neurite outgrowth, axonal transport and trophic signaling enhancement. Moreover, tau participates in cell signal transduction through the modulation of the activity of Src and Fyn kinases and PSD95 protein. In the nucleolar organizing region of cell, tau can also be involved in DNA repair and heat shock responses (left panel). Tau dysfunction leads to microtubule disintegration, tau filaments formation and intraneuronal signaling disorder and, as a consequence, to cell death (right panel).

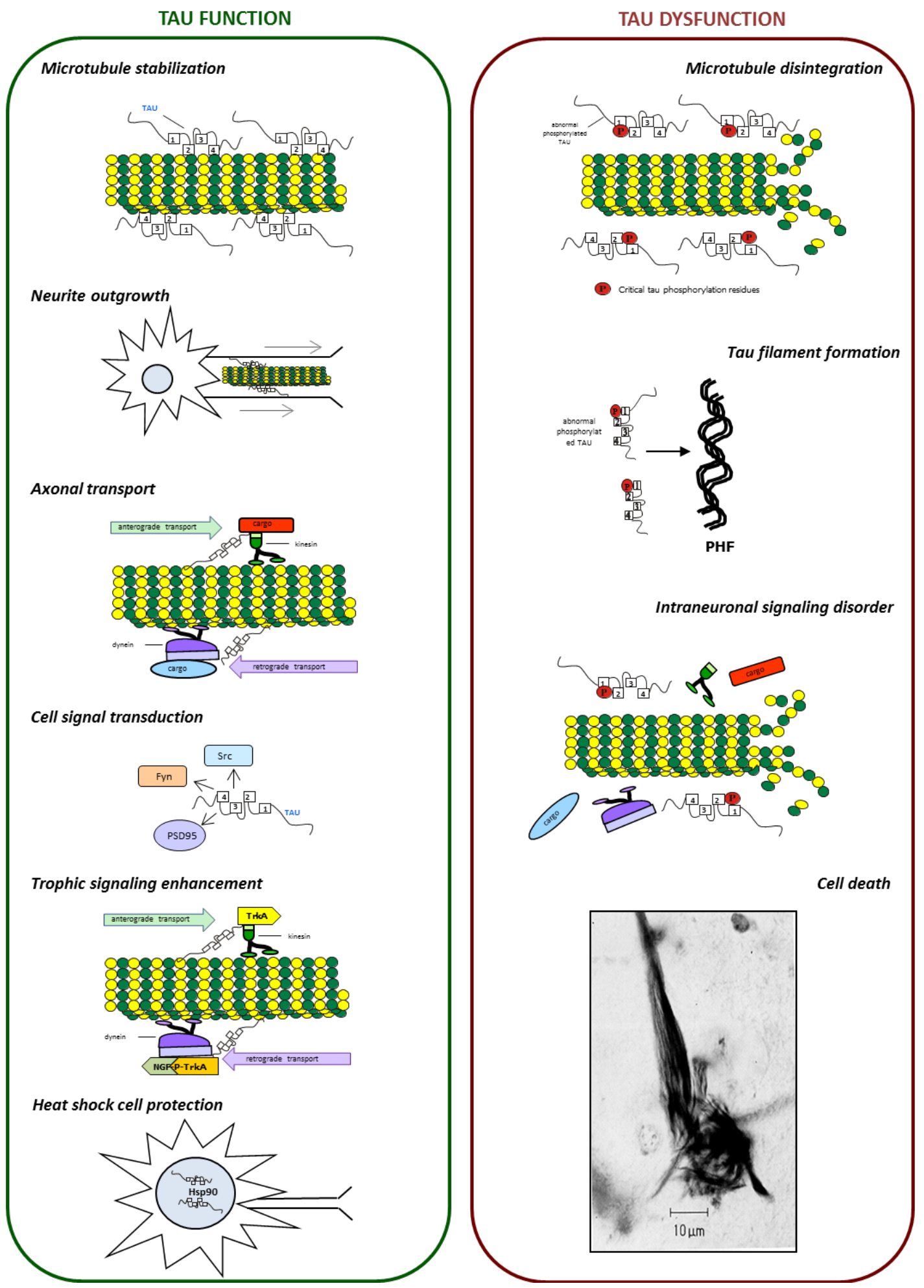


The adult forms of tau promote assembly of microtubules more actively than the foetal form [29]. The recent studies concerning the physical interaction between tau and microtubules indicated that, while all repeats contacted the microtubules, there were specific sequences that were strongly involved in the interaction [50]. These sequences included ${ }^{24}{ }^{\circ} \mathrm{KSRLQTAPV}^{248},{ }^{275} \mathrm{VQINKKLDLS}^{285}$ and ${ }^{297} \mathrm{IKHV}^{300}$. In addition, residues in the flanking regions as far upstream as S214 and as far downstream as L375 were also involved, with ${ }^{225} \mathrm{KVAVVRT}^{231}$ and ${ }^{370} \mathrm{KIETHK}^{375}$ having especially strong interactions [50,51]. Both sequences ${ }^{275}$ VQINKKLDLS ${ }^{285}$ and ${ }^{297} \mathrm{IKHV}^{300}$ are coded by exon 10 and this may explain why $4 \mathrm{R}$ tau isoforms interact with microtubules more strongly than $3 \mathrm{R}$ tau isoforms [52]. The repeat sequences are thought to directly bind microtubules through their positive net charge, which interacts with negatively charged residues of tubulin monomers [44]. Tau can bind outside and inside of microtubules, with its $N$ - and $C$-terminal domains [38,53].

Binding of tau to microtubules can take part in axonal transport and can interfere with the binding of motor proteins [12]. A gradient of tau along the axon with the highest level around the synapse [54] might facilitate the detachment of motor proteins from their cargo near the presynaptic terminal and in consequence might increase axonal transport efficiency [12]. As to the interactions with other cytoskeletal components, tau binds to spectrin and actin filaments [55,56]. This might allow tau-stabilized microtubules to interconnect with neurofilaments that restrict the flexibility of the microtubule lattices [57].

Tau can also act as postsynaptic scaffolding protein. As a scaffold protein, tau modulates the activity of Src tyrosine kinases, c-Src and Fyn, and facilitates c-Src-mediated actin rearrangements [58]. In the case of Fyn, it has been suggested that tau normally tethers Fyn to PSD-95/NMDA receptor signaling complex [4]. In the absence of tau, Fyn can no longer traffic into postsynaptic sites in dendrites. Although normally very little tau is present in dendrites, probably it is enough to ensure proper localization of postsynaptic components [4]. Tau can also act as a scaffold protein in oligodendrocytes, where it might connect Fyn and microtubules in order to enable processes extension [27].

Another function of tau is involvement in growth factor signaling [59,60]. Under NGF stimulation, tau is distributed at ends of cellular extensions, where it associated with actin in a microtubule-independent manner [55]. Tau facilitates signaling through receptors for NGF and EGF, what may increase the activity of the mitogen-activated protein kinase (MAPK). Some data suggest that phosphorylation of tau on threonine 231 is necessary for the growth factor-induced activation of the Ras-MAPK pathway [61]. It remains unverified whether tau interacts directly with growth factor receptors, but it may facilitate signaling by binding to adaptor proteins e.g., Grb2 [62].

\section{Post-Translational Modifications of Tau}

Tau is highly regulated and is subject to a complex array of post-translational modifications. It is modified by serine, threonine and tyrosine phosphorylation [63], isomerization [64], glycation [65], nitration [66], O-GlcNAcylation [67], acetylation [68], oxidation [69], polyamination [70], sumoylation [71], ubiquitination [72] and proteolytic cleavage (truncation) [73]. Abnormal post-translational modifications are proposed to be the main cause of the mechanism by which tau protein becomes a non-functional entity. Much of the evidence, to be discussed below, suggests that abnormal phosphorylation is a key event that triggers the pathological aggregation of tau in tauopathies. 


\subsection{Phosphorylation and Dephosphorylation of Tau Protein}

Protein phosphorylation is the addition of a phosphate group by esterification at three types of amino acids: serine, threonine and tyrosine. Phosphorylation is the most common tau post-translational modification described. So far, 85 phosphorylation sites have been identified in the tau molecule. The phosphorylation status of the tau is a consequence of the equilibrium between the amount and activity of protein kinases and phosphatases. In neurodegenerative diseases tau undergoes abnormal excessive phosphorylation.

\subsubsection{Tau Kinases}

Kinases which are involved in tau phosphorylation can be divided into three classes: proline-directed protein kinases (PDPK), non-PDPK protein kinases and tyrosine protein kinases (TPK).

\subsubsection{GSK-3}

Glycogen synthase kinase-3 (GSK-3), belongs to the PDPK class, and is a serine/threonine-specific kinase whose activity is regulated by phosphorylation. GSK-3 is inactivated through phosphorylation of serine 21 (GSK-3 $\alpha$ isoform) or serine 9 and 389 (GSK-3 $\beta$ isoform). The activation of GSK-3 depends on the phosphorylation at tyrosine 279 (GSK-3 $\alpha$ ) or tyrosine 216 (GSK-3 $\beta$ ) [74-76]. GSK-3 was identified as a tau protein kinase in the 1990s [77]. So far 42 GSK-3 phosphorylable sites were identified in tau. Among them 29 were phosphorylated in Alzheimer disease (AD) brains [11,78,79]. The level of GSK-3 in tauopathy seems to correlate with the progress of neurodegeneration. The postmortem analysis of brains from AD patients and age-matched control samples indicates that the level of GSK-3 is increased in neurodegeneration [80] and the activity of GSK-3 correlates with the increasing amount of NFTs [81]. Moreover, GSK-3 $\beta$ co-localizes with NFTs [82]. Additionally, studies performed on cultured neurons have shown that the GSK-3 inhibitor, lithium, protects cells against neurodegeneration $[83,84]$. Abnormally phosphorylated tau protein is also the main component of neurofibrillary tangles found in Parkinson's disease (PD) [85]. Increased tau phosphorylation at Ser396 by GSK-3 $\beta$ has been discovered in synapse-enriched fractions taken from PD brains [86]. Moreover, tau pathology has been identified in the brains of PD patients with leucine-rich repeat kinase 2 (LRRK2) mutations [87].

DJ-1 is a small protein, the product of a highly conserved gene that has been identified as one of the most frequently mutated genes in familial Parkinson's disease (PD). Recently, it has been postulated that familial PD-associated DJ-1L166P and DJ-1D149A mutations increase tau phosphorylation by increasing the activity of GSK-3 $\beta$ [88]. The link between tau phosphorylation and GSK-3 has been shown in studies performed on transgenic mice overexpressing mutant human tau (P301L, 4RON). This mutation is related to the tauopathy named frontotemporal dementia with Parkinsonism linked to chromosome 17 (FTDP-17). The treatment with lithium of the aforementioned transgenic mice led to a decrease in the level of tau phosphorylation and the level of aggregated, insoluble tau. A similar result was obtained when another GSK-3 inhibitor, AR-A014418, was used [89]. Moreover, recently the implication of GSK-3 in tau pathology has been confirmed using pR5 mice that express the P301L tau mutation found in familial forms of frontotemporal dementia [90]. 


\subsubsection{Cdk5}

Cyclin-dependent kinase $5(\mathrm{cdk} 5)$, originally purified as tau kinase II, is a serine/threonine kinase [91] which belongs to the PDPK class. Similarly, as with the case of GSK-3, cdk5 activity is regulated by phosphorylation. Three residues seem to be implicated in this process. Phosphorylation at tyrosine 15 activates cdk5, in contrast to phosphorylation at threonine 14 and at serine 159 that inhibits cdk5 activity [92]. Additionally, the activation of cdk5 requires the binding of an activatory subunit, either p35 or p25 which is generated by calpain-dependent proteolytic cleavage of p35 [92]. The cdk5 activator, p25, has a long half-life and is involved in aberrant cdk5 activity toward tau [93,94]. It has been shown that p25 accumulates in the tauopathic brains derived from AD patients. The p25/cdk5 holoenzyme phosphorylates tau and reduces its ability to bind to microtubules. Studies performed on primary neurons have shown that $\mathrm{p} 25 / \mathrm{cdk} 5$ alters cells morphology, causes cytoskeletal disruption and apoptotic cell death [95]. Silencing of cdk5 reduces the phosphorylation of tau in primary neuronal cultures and in the brain of wild type C57BL/6 mice. In a triple transgenic mouse model of $\mathrm{AD}$ disease, the knock-down of cdk5 strongly decreases the number of neurofibrillary tangles in the hippocampus [96]. Cdk5 also seems to be involved in the regulation of tau phosphorylation by GSK-3. Tau, cdk5, and GSK-3 are components of a 450-kDa complex in which cdk5 phosphorylates tau and primes it for phosphorylation by GSK-3 [97]. Recently, it has been shown that the effect of cdk5 on tau phosphorylation depends on the Pin 1 protein [98-100].

\subsubsection{JNK}

C-Jun amino-terminal kinase (JNK) belongs to the PDPK group of kinases and simultaneously to the family of serine and threonine mitogen-activated protein kinases (MAPKs). JNK phosphorylates tau at 12 sites, which were identified only in neurodegeneration and not in control conditions. Immunohistochemical analysis of JNK expression in $\mathrm{AD}$, Pick's disease (PiD), progressive supranuclear palsy (PSP) and corticobasal degeneration (CBD) unveiled its co-localization with tau aggregates [101]. Moreover the increased level of JNK has been observed in AD brains and its activated form (p-JNK) co-localizes with p-tau in neurons of AD patients [102,103].

\subsubsection{CK1}

Casein kinase 1 (CK1) is a family of protein kinases, non-PDPK, which in humans consists of six isoforms derived from distinct genes with further diversity generated by alternative splicing [104]. CK1 can phosphorylate tau at Ser202/Thr205 and Ser396/Ser404 in vitro and in cell culture, modulating its binding affinity for microtubules [105-107]. The distribution of CK1 delta (CK1 $\delta$ ) was studied by immunohistochemistry. CK1 $\delta$ co-localizes with NFTs in AD, Down syndrome (DS), PSP, parkinsonism dementia complex of Guam (PDC) and with Pick bodies in PiD [108]. Moreover, the mRNA of $\mathrm{CK} 1 \delta$ is upregulated in brain derived from AD patients. There was a 24.4-fold increase in $\mathrm{CK} 1 \delta$ mRNA in hippocampus, 8.04-fold in the amygdala, 7.45 in the entorhinal cortex and 7.30-fold in the mediotemporal gyrus of AD when compared to control brains [109]. 


\subsubsection{Dyrk1A}

Increased non-PDPK, Dyrk1A (Dual specificity tyrosine-phosphorylation-regulated kinase 1A) kinase immunoreactivity has been found in the cytoplasm and nuclei of scattered neurons of the neocortex, entorhinal cortex, and hippocampus in AD, DS, and PiD [110]. Dyrk1A protein phosphorylates the microtubule-associated protein tau at several sites, including Thr181, Ser199, Ser202, Thr205, Thr212, Thr217, Thr231, Ser396, Ser400, Ser404, and Ser422. Phosphorylation by Dyrk1A primes further phosphorylation of tau by GSK-3 at Thr181, Ser199, Ser202, Thr205, and Ser208 but not by cdk5 and PKA [111-113]. Tau phosphorylation at Thr212, Ser202 and Ser404 is the hallmark of $\mathrm{AD}$ and is significantly increased in Dyrk1A transgenic mice overexpressing human Dyrk1A [110]. Moreover, a study performed using a transgenic mouse model of DS, the Ts65Dn mice, confirmed the abnormal phosphorylation of tau upon increased Dyrk1A activity. Dyrk1A induced tau phosphorylation inhibited tau activity to stimulate microtubule assembly and promoted its self-assembly into filaments [109,110].

\subsubsection{AMPK}

Adenosine-monophosphate activated protein kinase (AMPK), non-PDPK, is a heterotrimeric serine/threonine kinase. The phosphorylation of tau by AMPK takes place at several residues and effects tau binding to microtubules [114,115]. In vitro assays showed that AMPK can directly phosphorylate tau at Thr231 and Ser396/404. Activated/phosphorylated AMPK (p-AMPK) was abnormally accumulated in cerebral neurons in tauopathies such as $\mathrm{AD}$, tangle-predominant dementia, PDC, PiD, and FTDP-17. Granular p-AMPK immunoreactivity was observed in apparently unaffected neurons devoid of tau inclusion, suggesting that AMPK activation preceded tau accumulation. Phospho-AMPK was not found in purified PHFs, indicating that p-AMPK did not co-aggregate with tau in tangles [114].

\subsubsection{MARKs}

The microtubule-affinity regulating kinases (MARKs) belong to the AMPK branch of the CAMK (calcium/calmodulin-dependent protein kinase) group of kinases [116]. MARKs belong to the non-PDPK group of kinases. The MARK protein family consists of four highly conserved members (MARK1-4). MARK kinases co-localize with NFTs, and the expression level of MARK proteins have been shown to be elevated in AD brains [117]. MARKs phosphorylate tau protein at the KXGS motif of its repeat domains. This phosphorylation leads to the detachment of tau protein from microtubules and in consequence, to destabilization of the cytoskeleton and the tau aggregation [118,119]. Tau phosphorylation by MARKs occurs at Ser262, 293, 324 and 356 [120,121]. Recently, it has been postulated that MARK4 is the crucial isoform of the MARK family which is implicated in the pathological phosphorylation of tau [122]. Studies concerning the regulation of MARKs activity have shown that MARK1 and MARK2 are activated by DAPK (death-associated protein kinase) and $\mathrm{DAPK}^{-} \Gamma$ mice brain displays a reduced phosphorylation of tau [123]. 


\subsubsection{PKA}

Cyclic AMP (cAMP)-dependent protein kinase (PKA) is a serine/threonine protein kinase which belongs to the non-PDPK class. PKA catalyzes tau phosphorylation in vitro and in vivo [124-126]. The phosphorylation of tau protein by PKA triggers subsequent tau phosphorylation by GSK-3 $\beta$ at several AD-relevant phosphorylation sites (Thr181, Ser199, Ser202, Thr205, Thr217, Thr231, Ser396 and Ser422) and simultaneously inhibits tau phosphorylation at Thr212 and Ser404. Additionally, prephosphorylation of tau by PKA slightly promotes tau phosphorylation by cdk5 kinase at Ser396 and inhibits its phosphorylation at Ser202, Thr212, Thr217 and Ser404 [123]. Abnormal phosphorylation of the tau protein by PKA kinase was confirmed in vivo [127]. It has been also observed that infusion of PKA activator, forskolin, into the lateral ventricle of brain in adult rats induced activation of PKA by several fold and concurrently enhanced the phosphorylation of tau.

\subsubsection{TPKI and TPKII}

Tau protein kinase I (TPKI) is a non-PDPK that can phosphorylate native tau isolated from normal brain, which is already phosphorylated to some extent, but it can not phosphorylate completely dephosphorylated tau. In contrast, TPKII can phosphorylate also the latter form of tau [128]. The tau residues phosphorylated by TPKII were Ser202, Thr205, Ser235, and Ser404, while those by TPKI were Ser199, Thr231, Ser396, and Ser413 [129]. Interestingly, the TPKII-dependent tau phosphorylation increased with increasing $A \beta$ concentration [130]. Similar interaction has been postulated in the case of TPKI [131].

\subsubsection{Tau Phosphatases}

Protein phosphatases (PPs), responsible for dephosphorylation of tau include: PP2B, PP2A, PP1 and PP5 [132].

\subsubsection{PP2B}

Protein phosphatase $\mathrm{PP} 2 \mathrm{~B}$ (calcineurin) is one of the major serine/threonine phosphatases in the brain the activity of which depends on $\mathrm{Ca}^{2+} /$ calmodulin. It consists of a catalytic $\mathrm{A}$ subunit with molecular mass of about $63 \mathrm{kDa}$ and a regulatory B subunit with molecular mass of about of $19 \mathrm{kDa}$, which binds $\mathrm{Ca}^{2+}$ and shares some degree of homology with calmodulin. The results obtained using phosphorylation-sensitive monoclonal antibodies AT-180 (against tau phosphorylated on Thr231) and AT-270 (for Thr181) show that reduction of PP2B activity in brain by antisense oligonucleotides led to persistent phosphorylation of tau at Thr181 and Thr231 [133]. Studies performed by Rahman et al. [134] showed that PP2B purified from AD brains efficiently dephosphorylated p-tau. The authors found also that the purified PP2B dephosphorylated tau obtained from AD brain at Ser199, Thr217, Ser262, Ser396 and Ser422 with the preferential dephosphorylation at Ser262 and Ser396. Interestingly, no significant difference in PP2B activity was found between control and AD brain in contrast to the results obtained by Qian et al. [135] who showed a 3-fold increase in PP2B activity in AD brain as compared to control one. The study of Kim et al. [136] concerning the PP2B phosphatase revealed that it can catalyze dephosphorylation of the Ser9 residue on GSK-3 $\beta$. The overexpression of a 
constitutively active PP2B mutant (A beta 1-401) increased GSK-3 $\beta$ activity and in consequence phosphorylation of tau. Thus, PP2B similarly to other phosphatases might also act indirectly on tau phosphorylation.

\subsubsection{PP2A}

Protein phosphatase 2A (PP2A) is a major brain tau phosphatase in vivo and thus its reduced activity might be a factor contributing to increased tau phosphorylation [137]. PP2A contains a catalytic $\mathrm{C}$ subunit, a scaffold-like A subunit and a regulatory $\mathrm{PR} 55 / \mathrm{B} \alpha\left(\mathrm{PP} 2 \mathrm{~A}_{\mathrm{T} 55 \alpha}\right)$ subunit. By using the NMR spectroscopy, Landrieu et al. [138] determined the dephosphorylation rates of p-tau by PP2A and showed kinetic data for the individual sites including Ser202/Thr205 and Thr231. The authors demonstrated the importance of the PR55/B $\alpha$ regulatory subunit of PP2A in this enzymatic process, and showed that phosphorylation at the tau Thr231 site inhibits dephosphorylation of the tau Ser202/Thr205 sites. This effect could be released by the Pin1 isomerase. Because this Pin1 effect is lost with the dimeric PP2A core enzyme (PP2A $)$ or when using a tau mutant, Thr231A that cannot be phosphorylated at residue 231, the authors proposed that Pin1 regulates the interaction between the PR55/B $\alpha$ subunit and the Thr231 epitope on tau. Protein phosphatase PP2A also dephosphorylates tau protein at Ser202/Thr205 in response to microtubule depolymerization [139]. Sontag et al. [140] reported that microtubule associated protein 2 (MAP2) is dephosphorylated by endogenous $\mathrm{PP} 2 \mathrm{~A} / \mathrm{B} \alpha$ (a major PP2A holoenzyme containing $\mathrm{PR} 55 / \mathrm{B} \alpha$ regulatory subunit), in the gray matter of bovine brain. By applying in vitro binding assays, the authors showed that $\mathrm{PP} 2 \mathrm{~A} / \mathrm{B} \alpha$ binds to MAP2c isoforms through a region encompassing the microtubule-binding domain and upstream proline-rich region. The protein-tyrosine kinase Fyn binds to the proline-rich RTPPKSP motif conserved in both MAP2 and tau and inhibits the interaction of $\mathrm{PP} 2 \mathrm{~A} / \mathrm{B} \alpha$ with either tau or MAP2c. This points to a critical role of Fyn-binding motif in MAP2 and tau in regulating signaling enzymes like PP2A/B $\alpha$ and Fyn. Dysfunction of these protein complexes is likely to contribute to tau deregulation, microtubule disruption, and altered signaling in tauopathies. All these data, together with the observation that PP2A is normally bound to microtubules in intact cells, suggest that the polymerization state of microtubules could modulate the phosphorylation state of tau at specific sites in normal and AD brain. Thus one can suggest that PP2A and its regulatory subunits might be a therapeutic target for Alzheimer's disease. It should be also mentioned that modulation of PP2A activity in AD brain might be due to its interaction with an inhibitor called SET/inhibitor 2 (I2) or ARPP-19 [141-143].

\subsubsection{PP1}

Protein phosphatase 1 (PP1) plays a fundamental role in many calcium-dependent cellular processes in neurons. Its catalytic subunit interacts with as many as 200 distinct regulatory proteins that target PP1 to specific subcellular locations where they influence its substrate specificity [144]. PP1 requires metal ions and its maximal activation is seen in the presence of $\mathrm{Mn}^{2+}$. Dephosphorylation of excessively phosphorylated tau obtained from AD brain by PP1 seems to be site-specific since PP1 preferentially dephosphorylated Thr212 (40\%), Thr217 (26\%), Ser262 (33\%), Ser396 (42\%) and Ser422 (31\%) [145]. Residue Thr212 was suggested to be dephosphorylated by PP1 only and not by 
PP2A or PP2B. This observation, although interesting, has not yet been confirmed. In other recent studies, protein phosphatase PP1 and tau have been linked to deficits in axonal transport [146,147].

\subsubsection{PP5}

Protein phosphatase 5 (PP5) is a phosphatase ubiquitously present in different mammalian tissues including brain, where it is abundantly expressed. Up to now, few physiological substrates of this phosphatase have been identified. Studies performed by Liu et al. [148] showed that dephosphorylation of p-tau by PP5 had a similar $K m$ to that found for phosphatase PP2A and was within the range of intraneuronal tau concentration. Phosphatase PP5 dephosphorylates tau at all 12 AD-associated abnormal phosphorylation sites studied, with different efficiency toward each site. The most favorable sites for action of PP5 on tau are Thr205, Thr212, and Ser409, less favorable sites being Ser199, Ser202, Ser214, Ser396 and Ser404 and the poorest site is Ser262. The activity but not the amount of PP5 was found to be decreased by about 20\% in AD neocortex which suggests that the attenuated activity of this phosphatase might be responsible for the overphosphorylation of tau in this disease. Recently, it has been shown that PP5 binds calcium binding proteins: S100A1, S100A2, S100A6 or S100B and that these S100 proteins activate PP5, when checked using tau as a physiological substrate [149]. The association of PP5 with S100 suggests a $\mathrm{Ca}^{2+}$-dependent mechanism of tau dephosphorylation. It is of note that the level of $\mathrm{Ca}^{2+}$ and of calcium binding proteins in most neurodegenerative diseases, including $\mathrm{AD}$, is deregulated [150].

\subsubsection{CacyBP/SIP}

Recent study [151] suggests that the calcyclin binding protein and Siah-1 interacting protein (CacyBP/SIP) protein, dephosphorylates tau. Similar to PP5, CacyBP/SIP phosphatase activity toward tau is affected by a calcium-binding protein, S100A6. The observed inhibition of CacyBP/SIP tau phosphatase activity might be a result of the influence of S100A6 on the CacyBP/SIP phosphorylation state. CacyBP/SIP is expressed in different tissues with the highest level being found in the brain. It is mainly a neuronal protein interacting with different targets. Among them are tubulin, actin and tropomyosin, which suggest that CacyBP/SIP might play a role in cytoskeletal reorganization. Furthermore, dephosphorylation of tau protein [151] and of ERK1/2 kinase [152] by CacyBP/SIP indicate that this phosphatase might play a role in signaling pathways leading to cell proliferation and differentiation. In our study [151], we have also found that in AD patients and line 1 tau transgenic mice, changes in cellular distribution of CacyBP/SIP were similar to those observed for two other microtubule proteins, $\beta$-tubulin and tau.

\subsubsection{TNAP}

Tau protein released on death of neurons may also induce a neurotoxic effect on hippocampal neurons by activation of the M1 and M3 muscarinic receptors. An essential component that links both effects is a tissue-nonspecific alkaline phosphatase (TNAP) [153]. TNAP is abundant in the central nervous system and is mainly required to keep control over the extracellular levels of phosphorylated compounds. TNAP dephosphorylates overphosphorylated tau once it is released upon neuronal death. 
Only the dephosphorylated tau behaves as an agonist of muscarinic M1 and M3 receptors, provoking a robust and sustained intracellular calcium increase finally triggering neuronal death. An increase in TNAP activity together with increase of protein and its transcript level were detected in AD patients. These observations indicate that TNAP promotes the neurotoxicity of extracellular tau which contributes to the spread of pathology in AD.

\subsection{Other Post-Translational Modifications}

The state of tau phosphorylation could be influenced by other post-translational modification. The temporal sequence of glycosylation, glycation, nitration, oxidation, polyamination, sumoylation and ubiquitination is unclear, but these modifications seem to occur before tau excessive phosphorylation and NFTs formation [154].

Glycosylation is the covalent attachment of oligosaccharides to a protein. There are two types of glycosylation: $N$-glycosylation and $O$-glycosylation. $N$ - and $O$-glycosylation result from the attachment of a sugar on the amine radical of asparagine on the hydroxyl radical of serine or threonine, respectively. Protein tau can be $O$-GlcNAc-ylated $(O$-glycosylation achieved by the engraftment of $\mathrm{N}$-acetyl-glucosamine) in vitro in recombinant systems and in some transfected cell-lines in culture [155]. In vivo, $O$-GlcNAc-ylation has been shown to reduce tau phosphorylation in rat cortex and hippocampus [156]. Conversely, biochemical evidence for tau to become $O$-GlcNAc-ylated was not obtained in the study of Borghgraef et al. [157] in Tau. P301L mice chronically treated with Thiamet-G, $\beta$ - $N$-acetyl-glucosaminidase inhibitor. In AD patients, a negative correlation has been reported between $O$-GlcNAcylation level and tau phosphorylation, suggesting that $O$-glycosylation of tau negatively regulates its phosphorylation [158]. Tau proteins from brains of AD patients and not that from brains of control patients were found to be non-physiologically glycosylated. On the basis of findings described by Takahashi et al. [159] the first step in the cascade of events leading to final tau modification is a down-regulation of tau glycosylation which cause the conformational changes leading to exposure of sites for their phosphorylation. The down-regulation of glycosylation and over-activation of GSK3 $\beta$, in turn facilitates abnormal tau phosphorylation.

Some evidence suggests that tau glycation prevents tau degradation and promotes its accumulation [160]. Moreover, glycation triggers the production of free radicals amplifying oxidative stress, which in turn increases tau phosphorylation [161]. By this mechanism, tau can be oxidized at C322, leading to PHF assembly [69]. Furthermore, oxidative stress promotes tau nitration which indicates that tau glycation can indirectly induce both tau oxidation and nitration, leading to tau phosphorylation and oligomerization [162]. Polyamination promotes NFT formation [163] and, together with tau glycation and nitration may render abnormally phosphorylated tau less prone to biochemical degradation by ubiquitin/proteasome system [164,165]. Subsequently, tau sumoylation can counteract ubiquitination and thus promotes tau aggregation. In this way sumoylation may control level of aggregates of tau [166]. 


\section{Proteins Interacting with Tau}

As described above, tau protein has several functions in the nerve cells. These functions are supported by a large number of other proteins, which include proteins that affect the phosphorylation of tau, and other proteins relevant to this modification. These proteins are discussed below.

\subsection{Amyloid- $\beta$}

Apart from showing nerve and synapse loss, the brains of patients with AD are characterized not only by neurofibrillary tangles NFTs but also by amyloid- $\beta$ (A $\beta$ )-containing plaques. $A \beta$ is a group of peptides that are structurally homologous, but with different chain length, containing 39-42 amino acids. A $\beta$ is processed from a larger amyloid precursor protein (APP) [167].

Results from both cellular and transgenic animal models indicate that tau protein is essential for A $\beta$-induced neurotoxicity [168]. In the early 90s the "amyloid cascade hypothesis" was presented. It was postulated that formation of neuritic plaques would stimulate subsequent pathological events, including the formation of NFTs and disruption of synaptic connections, which would lead to reduction in neurotransmission, death of tangle-bearing neurons and dementia [169].

Although $A \beta$ and tau protein become toxic through the different mechanisms, human, animal and in vitro studies have found a direct link between $\mathrm{A} \beta$ and tau in causing toxicity in $\mathrm{AD}$. Ittner and Götz [170] suggested three possible ways of interaction between both proteins: (1) A $\beta$ drives tau pathology; (2) synergistic toxic effects of $A \beta$ and tau; and (3) tau may mediate $A \beta$ toxicity. The same authors put forward the "tau axis hypothesis" which implies that the converging point of the pathological effects of both proteins is a dendritic area of nerve cells. The hypothesis suggests that increased concentrations of tau within the dendrites can make neurons more vulnerable to damage caused by $A \beta$ in the postsynaptic dendrites [170].

There are strong experimental data indicating that tau is essential for $A \beta$-induced neurotoxicity. For example, cultured hippocampal neurons from tau knock-out mice are protected against $A \beta$ pathology. The tau silencing in cultured hippocampal neurons from wild-type mice showed that tau was required for pre-fibrillar $A \beta$-induced microtubule disassembly [168]. Also, reduction of tau prevents $A \beta$-induced defects in axonal transport of mitochondria [171]. A $\beta$ and pathological P-tau co-localize in $\mathrm{AD}$ synapses [172,173]. Other studies revealed that $\mathrm{A} \beta$ and/or chronic oxidative stress are critical for development of tau pathology, including tau excessive phosphorylation and NFT formation $[161,174]$.

\subsection{Pin1}

Pin1 is a peptidyl-prolyl isomerase that recognizes a specific motif of a phosphorylated serine or threonine residue preceding a proline residue. Pin1 was first described as a nuclear protein which can regulate a subset of mitotic and nuclear substrates, but its function is not restricted to cell cycle control but is extended to multiple cellular processes such as transcription and apoptosis. Pin 1 was shown to be involved in tauopathies since Pin1 dysfunction may have critical consequences on tau pathological aggregation and neuronal death [175]. Recent study performed by Kimura et al. [100] shows that Pin1 stimulates dephosphorylation of tau phosphorylated by cdk5. Pin1 binds to tau and stimulates its 
dephosphorylation at all cdk5 phosphorylation sites including Ser-202, Thr-205, Ser-235, and Ser-404.Tau carrying the FTDP-17 mutation, P301L or R406W, showed slightly weaker binding to Pin1 than wild type tau, suggesting that FTDP-17 mutations induce cdk5-dependent increased tau phosphorylation by reducing its interaction with Pin1. These results demonstrate that mutation of tau may change the conformation of tau, thereby suppressing dephosphorylation and potentially contributing to the etiology of tauopathies [99,176].

Exposure of neurons to $A \beta$ results in dephosphorylation of Pin1, its activation and dephosphorylation of tau on Thr231. This effect might be prevented by Pin1 inhibitor or by okadaic acid which inhibits PP2A [177]. Also, it was found that Pin1 is responsible for the transient modulation of tau phosphorylation at Ser199, Ser396, Ser400 and Ser404 in response to A $\beta$ [178]. Some other data suggest that Pin1 is also involved in the regulation of APP processing and A $\beta$ production [11]. Phosphorylation of Thr743 in APP allows Pin1 to bind to APP [179]. Thus, the observed loss in Pin1 in advanced AD is in agreement with the reported effects of Pin 1 in cellular and animal models.

\subsection{Fyn Kinase}

Fyn is a membrane-anchored non-receptor tyrosine kinase from the Src-family. Recent evidence indicates the importance of tau interactions with Fyn during $A \beta$-mediated neurodegeneration $[4,180,181]$. Tau phosphorylated by Fyn on Tyr18 [182,183] has been detected in the proportion of tangles in early AD brain [63,184]. Tau interacts with Fyn by its SH3 domain [62]. Binding of tau to SH3 domain is regulated by phosphorylation of tau on specific serine/threonine residues [185].

Tau binds to Fyn in dendritic spines, and this interaction regulates $N$-methyl-D-aspartate (NMDA) receptor signaling [4]. Pathological tau may participate in localization of Fyn in the postsynaptic compartment, where it phosphorylates NMDA receptor subunits which leads to an increase in $\mathrm{Ca}^{2+}$ and to excitotoxicity [186]. Ittner et al. [4] have suggested that interaction between tau and Fyn in dendrites plays a critical role in mediating $A \beta$-induced neurotoxicity by influencing the stability of complexes formed by NMDA receptor and postsynaptic density protein 95 (PSD-95). It is conceivable that tau and Fyn might exist in a complex with NMDA receptors and PSD-95 in neurons. Activation of signaling pathways that lead to increased activity of Fyn could therefore affect the tyrosine phosphorylation of tau, which could potentially modulate complex formation, and result in altered trafficking into neuronal membrane compartments. Additionally, Fyn-tau interaction plays an important role in oligodendrocytes, where it regulates the outgrowth of cytoplasmic processes on the glial cell body. Impairment of the tau-Fyn interaction and excessive phosphorylation of tau leads to hypomyelination of axons [27]. All these findings suggest that tau-Fyn interaction is important for tau localization in neurons and has significant implications during the progression of neurodegenerative diseases.

\subsection{Heat Shock Proteins}

Heat shock proteins, called also molecular chaperones, are highly conserved proteins. They are involved in most aspects of protein synthesis, folding, trafficking and assembly of multiprotein complexes $[187,188]$. 
The emergence of molecular chaperones as key regulators of tau processing suggests that conformational changes of this protein may be important events in the pathogenesis of $\mathrm{AD}$ and other tauopathies. In a cellular environment, post-translational processing of tau is regulated by the chaperone network [189].

The Hsp70 family consists of 13 proteins, some of them were first described as regulators of tau. The most abundant proteins present in the cytoplasm are the constitutive heat shock cognate 70 protein (Hsc70) and the inducible heat shock protein Hsp70. These two proteins share 92\% homology in the amino acid sequence. Both have highly conserved $N$-terminal ATPase domains and substrate-binding domains situated just above more variable/regulatory domain [190]. Hsp70 has a dual role with tau. It stabilizes binding of tau to microtubules as well as promoting tau degradation in combination with chaperone-associated ubiquitin ligase (CHIP) [189]. Hsc70 and Hsp70 bind tau, but in the cytosol, endogenous Hsc70 is more abundant than Hsp70 [190]. Recent study has demonstrated that Hsc70 regulates the association of tau with microtubules [191]. The authors found that Hsc70 facilitates MC1 conformation, which is an epitope created when the amino acids at residues 7-9 interact with residues 312-342. They speculated that tau folding into the MC1 conformation after microtubule destabilization could be a protective mechanism to control the disordered nature of tau and prevent self-assembly in neuron. They also found that Hsc70 enhances tau-mediated microtubule polymerization. The work from Miyata et al. [188] has shown that inhibition of the ATPase activity of Hsp70/Hsc70 promotes proteasomal degradation of tau while its activation results in tau accumulation. Furthermore, such inhibition was able to reduce p-tau levels and improve cognition in a transgenic mouse model.

Heat shock protein 90 (Hsp90) was also described as a tau-binding protein [192]. It has been shown that Hsp90 promotes tau phosphorylation by its ability to regulate GSK-3 $\beta$. These data may suggest that Hsp90 allows accumulation of highly phosphorylated tau species. Additionally, other groups report that inhibition of Hsp90 by 17-AAG and other inhibitors reduces cellular levels of two p-tau species, p-Tau(Ser-202/Thr-205) and p-Tau(Ser-396/Ser-404) both of which are important for AD pathogenesis [193]. Dickey et al. [194] showed that protein kinase Akt and ubiquitin ligase CHIP co-regulate tau degradation through coordinated interactions involving Hsp90. They suggest that, by regulation of the CHIP/Hsp90 complex, Akt reduced tau ubiquitination and slowed its degradation. In addition, Akt enhances phosphorylation of tau at Ser262/Ser356, a site that is not recognized by the CHIP/Hsp90 degradation complex.

\subsection{FKBP51 and FKBP52 Immunophilins}

In general, immunophilins are cytoplasmic proteins and their physiological function is that of a chaperone with peptidyl-prolyl cis-/trans-isomerase (PPIase) activity. FKBP51 and FKBP52 are both involved in tau protein turnover [195]. FKBP51 overexpression preserves tau in cells and protects it from ubiquitination, perhaps by twisting tau in such a way as to prevent access to ubiquitin ligases. It was also proposed that phosphorylation of tau drives the association of FKBP51 with tau, suggesting that as tau dissociates from the microtubules, it is recognized by the chaperone machinery and primed for dephosphorylation. FKBP51 promotes the association of tau with Hsp90 which leads to its dephosphorylation [192] and its overexpression enhanced neuronal loss in the rTg4510 tau transgenic mouse model [196]. FKBP51 can work with Hsp90 to produce oligomeric tau in the brain and prevent 
tau clearance thus increasing tau toxicity. This activity of Hsp90 in cooperation with FKBP51 is in contrast to the effects of other chaperones that have been shown to enhance tau clearance, block amyloid formation, and decrease tangle load in the brain.

Chambraud et al. [197] reported that FKBP52, which is abundant in brain, binds directly and specifically to tau, especially to its highly phosphorylated form. Both proteins co-localize in the distal part of the axons of cortical neurons where FKBP52 decreases tau ability to promote microtubule assembly. Furthermore, overexpression of FKBP52 in differentiated PC12 cells prevented the accumulation of tau and resulted in reduced neurite length.

\section{6. $\alpha$-Synuclein}

$\alpha$-Synuclein $(\alpha-\mathrm{SN})$ has been found in the Lewy body inclusions that are pathognomic for Parkinson's disease (PD). It has been suggested that $\alpha$-SN may be involved in pathogenesis of $\mathrm{AD}$ [198] based upon the fact that it binds to tau and primes it for action of kinases. $\alpha$-Synuclein is abundant in the brain and interacts with synaptic vesicles at presynaptic terminals. There is also evidence for its chaperoning action for other proteins. In biochemical properties $\alpha$-synuclein resembles tau protein in several respects: it is an acidic, heat-stable, unfolded protein that has characteristic repeats. It aggregates when it is overexpressed [199]. Recent studies show that $\alpha$-synuclein has the ability to stimulate tau phosphorylation by GSK-3 $\beta$ through formation of a protein complex with these two proteins. The expression of $\alpha-\mathrm{SN}$ is promoted by oxidative stress. Accumulation of $\alpha$-SN induced by such stress may lead to the excessive phosphorylation of tau by GSK-3 $\beta$ [200].

The studies concerning the physiological correlation between tau and $\alpha$-synuclein have also demonstrated that phosphorylated tau is present in Lewy bodies, which are cytoplasmic inclusions formed by abnormal aggregation of $\alpha$-SN. The PD-linked neurotoxin 1-methyl-4-phenyl-1,2,3,6-tetrahydropyridine (MPTP) increases the phosphorylation of tau as well as the protein level of $\alpha$-SN in cultured neuronal cells, and also in mice [200]. Other studies [201] have shown, that $\alpha$-SN interacts directly with tau and stimulates its phosphorylation by protein kinase A (PKA). PHF-tau is phosphorylated on at least 21 sites. One of these sites, Ser262 is uniquely located within the first microtubule-binding region of tau. Phosphorylation at this site alone was found to detach tau from microtubules, cause microtubule instability, and make tau neurotoxic in Drosophila and in cultured primary neurons [202]. PKA phosphorylates tau at both Ser214 and Ser262. It has been discovered that in the presence of $\alpha$-synuclein, PKA phosphorylates Ser262 to a higher extent than in its absence. These results indicate that $\alpha$-synuclein is a regulator of phosphorylation of tau at Ser262. Phosphorylation of tau at Ser262 depends also on pathogenic mutations in $\alpha$-synuclein.

\subsection{PACSIN1}

PACSIN1 (or SYNDAPIN1) is a neuron-specific member of the cytoplasmic adapter proteins PACSINs family. All PACSINs represent a group of the larger Pombe Cdc15 homology (PCH) protein family, which participate in rearrangements of actin networks during vesicle formation and transport [203]. In their study Grimm-Günter et al. [204] have shown that PACSINs contribute to tubulin nucleation and retard microtubule regrowth. They also suggested that other PCH proteins have been linked with microtubule and/or centrosome function, mainly by their $N$-terminal F-BAR domains. 
Additionally, reduction of these proteins levels delay, but do not prevent, tubulin polymerization. Neuron-specific PACSIN1 contains a highly conserved SH3 and F-BAR domain, sequence determining PACSIN1 involvement in F-actin cytoskeleton organization and membrane trafficking [205]. PACSIN1 interacts with vesicle-associated proteins, including large GTPase DYNAMIN1 and EHD proteins, and it plays an important role in endocytosis and endosomal recycling.

PACSIN1 was also identified by Liu et al. [205] as a tau-binding protein. PACSIN1-tau interaction reduces tau affinity to microtubules and suppresses tau-induced microtubule polymerization, stability and bundling. These authors used a model system of cultured dorsal root ganglia (DRG) neurons and found that PACSIN1 blocking resulted in a higher number of straight and spread microtubules and decreased axonal length with a greater number of primary axonal branches.

\section{Tau Dysfunction}

\subsection{Tau Aggregates}

Tau aggregates display different morphologies in different tauopathies. The type of aggregate formed is determined by the tau isoforms involved and the presence of mutations in the tau gene [206]. In neurodegenerative diseases, such as $\mathrm{AD}$ and $\mathrm{AD}$-related tauopathies (foldopathies) [207], tau is highly phosphorylated and has a tighter more folded conformation and is remarkably more susceptible to aggregate than non-phosphorylated tau [208,209]. The increased pool of soluble tau undergoes additional conformational changes, which may support initial steps of tau assembly into filaments [210]. Much evidence confirms that abnormal phosphorylation converts tau from a biologically functional molecule into a toxic protein, and that this is responsible for the polymerization of tau into paired helical filaments (PHFs), pathological structures observed in AD [211,212]. The PHFs in turn bundle into neurofibrillary tangles or neuropil threads leading to neuronal death. Neurons accumulate misfolded protein deposits recognized by antibodies against tau of 55 to $69 \mathrm{kDa}$ and ubiquitin, and this is accompanied by PHF formation and tubulin fragmentation and deacetylation [208,213]. The deposits tend to fill the basal pole of pyramidal neurons, encompassing the area of the axon hillock and basal dendritic branches.

Many scientists postulated that abnormal and excessive phosphorylation precedes tau aggregation and these aggregates are believed to be the toxic species in tauopathies. However, some experimental evidence suggests that filamentous inclusions of tau may not be responsible for neuronal dysfunctions [214-216]. Cowan and co-authors [217,218] have shown that highly phosphorylated wild-type human tau causes behavioral deficits resulting from synaptic dysfunction, axonal transport disruption, and cytoskeletal destabilization in vivo in the absence of neuronal death or filament/tangle formation. Physiological and pathological tau species include: monomers, dimers/trimers, small soluble oligomers, insoluble granular tau oligomers, filaments, pretangles, large non-fibrillar tau aggregates, neurofibrillary tangles and ghost tangles [219]. There is a body of evidence, which is still not broadly accepted, that among of all these tau species small soluble tau oligomers are the most toxic and filamentous and fibrillar tau is neither necessary nor sufficient for tau-induced toxicity, and may even represent a neuroprotective strategy [218-221]. Tau dimers and oligomers are considered to be intermediates between soluble tau monomers and insoluble tau filaments. The data suggest that dimers 
and trimers of tau can suppress axonal transport and cause significantly greater loss of synapses and neurons resulting in stronger memory deficits than tau monomers and fibrils [222,223]. Berger et al. [224] in rTg4510 mouse model and Sahara et al. [225] in human AD brains have shown that tau $140-\mathrm{kDa}$ dimers appeared at very early stages of disease when memory deficits were evident in the absence of tangle formation. It has been suggested that formation of NFTs is a protective response that ultimately fails [226] (Figure 2).

Figure 2. Proposed sequence of stages leading to tau pathology. Detachment of tau from microtubules increases amount of misfolded tau monomers. Monomers aggregate into small soluble tau oligomers. Small soluble tau oligomers and tau monomers can proceed to form granular tau oligomers (GTOs). Probably both, small oligomers and GTOs form paired helical filaments (PHFs) but GTOs are considered to be the main precursors of PHFs. Subsequently PHFs spontaneously aggregate into neurofibrillary tangles (NFTs).

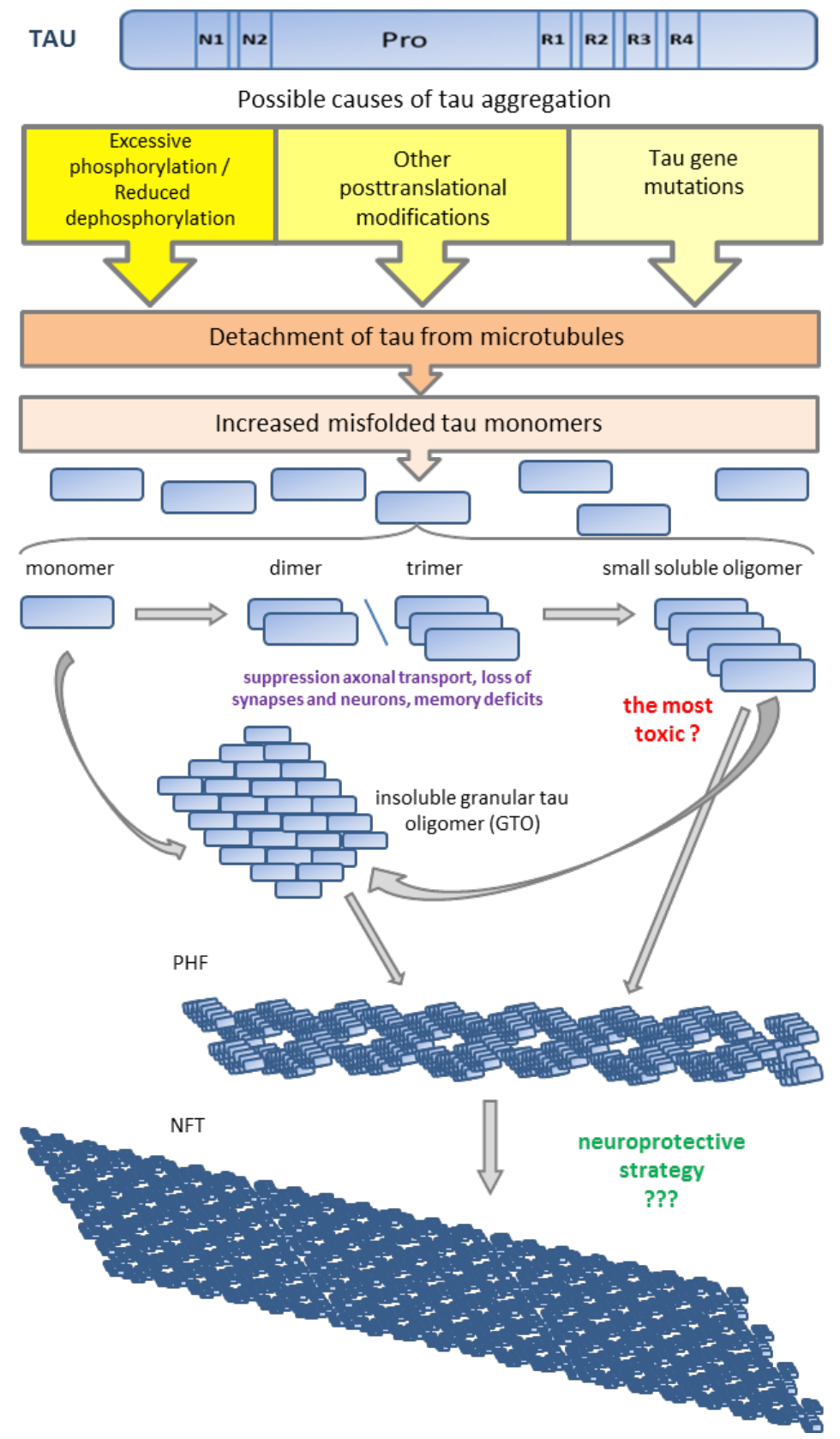




\subsection{Tau and Microtubule Instability}

The interaction between tau and microtubules is greatly decreased by tau phosphorylation at Ser262 and Ser356 [85]. Other phosphorylation sites shown to have some effects on microtubule association are Ser205, Ser212, Ser214, Thr231, Ser235, Ser396 and Ser404 [227-229]. However, the mechanism leading normal tau to become overphosphorylated and disengaged from microtubules to form tau inclusions remains unclear. Some scientists postulated that in this process reversible lysine acetylation is engaged [68,230,231]. Since acetylation neutralizes charges in the microtubule-binding domain, aberrant acetylation may interfere with the binding of tau to microtubule leading to tau dysfunction [230]. Lys280, in the region ${ }^{275}$ VQINKKLDLS ${ }^{285}$, is one of three lysine residues most critical in modulating tau-microtubules interactions. Increase tau acetylation on Lys280, impairs the interaction with microtubules and increases the pools of cytosolic tau available for pathological aggregation [68].

Although most data on microtubule assembly and pathological tau have been obtained using PHF-tau from AD patients, there is agreement that PHF-tau proteins fail to bind with microtubules [232,233]. Abnormally phosphorylated tau isolated from brain homogenates of AD patients (AD p-tau) comprises little overall activity, but dephosphorylation with alkaline phosphatase recovers its normal activity to a level similar to acid-soluble tau. Microtubule assembly is inhibited in the presence of $\mathrm{AD}$ p-tau while tau-tau interactions are facilitated. These studies implicate abnormal phosphorylation of tau in the breakdown of microtubules in affected neurons in AD not only because the altered protein has little microtubule-promoting activity but also because it interacts with normal tau, thereby reducing the amount of "healthy" tau even further. The collapse of microtubules is an important event of neurofibrillary degeneration induced by the aggregation of tau proteins in nerve cells. Findings of the last studies show that interactions between tau and microtubules are more complex than they thought. Some data [51] provide evidence that microtubules promote tau oligomerization on their surface. Additionally Duncan and Goodson [234] have found that microtubules induce rapid formation of tau filaments in vitro and that this process probably does not require phosphorylation of tau. It is a question if tau filaments assembly by microtubules might play a role in the formation of Alzheimer's-associated PHF or NFTs in vivo.

A corollary of the abnormalities in tau-microtubule interactions is the progressive break-down of the cytoskeleton, synaptic withdrawal [235,236], and after a brief period of survival, neuronal death and subsequent dementia [237,238]. The cell will experience lysis so that tau is liberated into the extracellular space. Here, tau has high affinity to molecules like sulfated glycosaminoglycans (sGAG), which further promote its polymerization, and upon glycation of the polymers stabilize tau into extracellular neurofibrillary tangles [239].

\subsection{Tau and Neuronal Transport Defects}

In postmitotic neuronal cells, one likely tau/microtubule-dependent function whose abnormality could easily lead to neuronal cell death is axonal transport [240,241]. Indeed, several neurodegenerative disorders are linked to disturbances in cellular cytoskeleton which controls polarized cargo trafficking pathways in neurons [242-244]. 
The microtubule and F-actin cytoskeleton might act as specific transport roads for intraneuronal trafficking. In the axon and dendrites, transport occurs bidirectionally, from the cell body to the periphery (anterograde transport) and from the periphery to the cell body (retrograde transport). These different directions of transport depend on the polarity of the cytoskeletal tracks. Microtubules are the polar structures: in the axon and the distal dendrites, the plus end (the fast growing end) points distally, whereas in the proximal dendrites, the polarity is mixed [245].

Motor proteins are responsible for the intracellular transport of a wide variety of components and for positioning them along the axon with high spatial-temporal precision. Three different classes of motors are involved in this task: dynein and kinesin, which transport cargoes toward the minus and plus ends of microtubules, respectively, and myosin, responsible for the transport along actin filaments [246-248]. Members of the kinesin superfamily of proteins (KIFs) [249] are known to drive anterograde axonal transport. Cytoplasmic dynein is the major minus end-directed microtubule motor in the neuron and is involved in retrograde axonal transport [250].

The tau, both as microtubule stabilizing and scaffolding protein could be involved in intraneuronal transport. Neurons containing the polar PHFs exhibit severely impaired anterograde transport along axons as well as basal dendrites; transport in apical dendrites is also impaired but in a retrograde-specific manner [251]. New insight into the role of axonal transport in neurodegenerative diseases stems from the observation that proteins accumulated in AD brains can modulate kinesin-1 receptors [252,253]. Overexpression and mislocation of tau proteins appear to modulate kinesin-1 based transport [147,241] by direct inhibition of motors on microtubule tracts, and this can lead to transport disruption for numerous cargoes, including APP vesicles, mitochondria, and peroxisomes, which could explain the energy deprivation and the oxidative stress sensitivity of AD neurons $[249,254]$. Disturbance of anterograde transport of microtubules slows down exocytosis and affects the distribution of mitochondria which become clustered near to microtubule organizing center (MTOC). The absence of mitochondria and endoplasmic reticulum in the peripheral regions of axons cause a decrease in glucose and lipid metabolism and ATP synthesis and loss of calcium homeostasis [16,255] that leads to a distal degeneration process.

\subsection{Tau and Neurotrophin Signaling}

Since tau controls the bidirectionality of axonal motor-driven transport in a concentration-dependent manner and differentially modulates the kinesin and dynein activity along microtubule tracks [12], defective intracellular trafficking of cargoes, including neurotrophins, could be due to an increased expression level of this protein [256-258] or to its altered intracellular localization [259] or excessive phosphorylation [231,260]. To this regard, the finding that the retrograde transport of I-125-NGF and activated TrkA receptors is inhibited by colchicine, a drug that interferes with the polymerization of microtubules [261,262], suggests that an altered function of tau protein may account for age-related deficiency of long-range neurotrophin signaling in cholinergic neurons. There is good evidence that the retrograde axonal transport of the active NGF-p-TrkA complex involves dynein [263-266], because inhibition of the dynein ATPase activity reduces the retrograde axonal transport of exogenous ${ }^{125}$ I-labelled NGF in sympathetic and sensory neurons in vivo [267]. Moreover, TrkA can directly associate with the juxtaposed membrane domain of dynein 
light chains [265] and phosphorylated TrkA in vesicles can attach and be transported within dynein motors [263]. One candidate protein that is implicated in TrkA transport is a light chain of the dynein motor complex, Tctex-1. Co-immunoprecipitation experiments from brain lysates demonstrated that TrkA, Tctex-1, and dynein form a protein complex [268]. Functional dynein-microtubule network is necessary for TrkA signaling to intracellular Rap1 and MAPK1/2 [269].

The hypothesis that the failure of tau-mediated axonal transport might be responsible for the lack of trophic support in aged or AD brains [59,60,270,271] is supported by several findings. In our study [59], we injected fluorogold (FG) into neocortex and hippocampus of young adult and 24 month old rats and confirmed that the number of retrogradely labeled FG positive neurons was significantly lower in subdivisions of the basal forebrain of aged rats. At the same time, tau immunostaining was restricted to neurites in neurons of the septo-hippocampal projection in young rats, but displayed a mainly somatodendritic distribution in aged rats. This redistribution of tau was confirmed by other immunohistochemical markers against p-TrkA, beta-NGF, p-Tau404 and p-Tau231, and GSK-3 $\beta$, which can phosphorylate serine 404 and threonine 231 [60]. Apart from an overall lower intensity of p-TrkA immunostaining in cortex and hippocampus of aged rats, immunoreactivity for all proteins was high and localized to the soma in old, and to the axonal and at a somewhat lower intensity to the dendritic compartment in young animals. Our data reveal that during aging expression of GSK-3 $\beta$ and three tau protein substrates are reduced in axons and this may severely compromise the efficiency of retrograde cytoskeletal transport.

Lazarov et al. [272] report that the anterograde fast axonal transport (FAT) of APP and Trk receptors is impaired in the sciatic nerves of transgenic mice expressing two independent familial Alzheimer's disease-linked PS1 mutations. Furthermore, familial Alzheimer's disease-linked PS1 mice exhibit a significant increase in GSK-3 $\beta$-mediated phosphorylation of the cytoskeletal proteins tau and neurofilaments in the spinal cord, which correlate with motor neuron functional deficits. It was also shown [273] that the loss of the $N$-terminal 25 amino acids of tau, which probably affects its interaction with dynactin/dynein motor complex [274], occurs in cellular and animal models of AD-like neurodegeneration induced by NGF signaling interruption. A crucial role of tau modifications in NGF-dependent neuronal survival was reported by Amadoro et al. [168]. They found that an early, transient and site-specific GSK-3 $\beta$-mediated tau overphosphorylation (3-6 h after NGF withdrawal) at two AD-relevant pathological epitopes (Ser262 and Thr231) is temporally and causally related with an activation of the endogenous amyloidogenic pathway in NGF-deprived hippocampal primary neurons [275].

\section{Conclusions and Perspectives}

Comprehensive investigations have revealed a role for tau protein in the neuronal cytoskeletal collapse in aging and neurodegenerative tauopathies. Highly phosphorylated tau detaches from microtubules and becomes retrogradely transported to the soma where it accumulates as aggregates of tau and ultimately neurofibrillary tangles. Control of tau phosphorylation by inhibiting tau kinases seems a feasible strategy to prevent tau aggregation and its associated pathological effects. Tau excessive phosphorylation appears to be required, but is not sufficient alone, to induce tau aggregation, other tau post-translational modifications are certainly required. However, tau protein 
regardless of its post-translational modifications, can also be toxic per se, and the suppression of tau protein blocks A $\beta$-induced toxicity and reduces memory deficit. Such data suggest that reduction of the overall tau levels may constitute a neuroprotective strategy to prevent tauopathies. Therefore, studying tau regulation at the transcriptional and translational levels is of great interest in further understanding of the physiological role of tau and its involvement in human pathologies.

Depletion of axonal tau protein will compromise active transport processes and, as exemplified for cholinergic neurons, impinge on the trophic support mechanism involving NGF and its receptors. It is worth noting that collapse of the cytoskeleton may have consequences for a number of processes. These may include axonal and dendritic transport systems, affecting the distribution of proteins, signaling molecules and organelles throughout the cell. Maintaining neuronal shape and contacts with neighboring cells through synaptic afferents and efferents will also be affected. Deterioration of these processes leads to neurodegeneration, neuronal cell death and cognitive impairment. Therefore, prevention of tau dysfunction and maintenance of the neuronal cytoskeleton may provide important therapeutic strategies for the treatment of $\mathrm{AD}$ and other tauopathies.

\section{Acknowledgments}

The authors wish to thank Charles R. Harrington from the University of Aberdeen for review and valuable comments on the manuscript. This work has been supported by WisTa Laboratories Ltd. and by grants from the National Science Centre to Anna Filipek (N N303 548439) and to Anna Gasiorowska and Grazyna Niewiadomska (nr 2011/01/D/NZ7/04405), and by statutory funds from the Nencki Institute of Experimental Biology.

\section{Author Contributions}

Each author has participated sufficiently in the work to take public responsibility for appropriate portions of the article content.

(1) Authors who made substantial contributions to conception and design of the review: G. Niewiadomska, A. Filipek, A. Mietelska-Porowska, M. Goras, and U. Wasik

(2) Authors who participate in drafting the article:

G. Niewiadomska-Abstract, Introduction, Paragraph 3 and 6, Conclusions, Figures 1 and 2

A. Mietelska-Porowska-Paragraphs 2, 3, and 4.2, Figures 1 and 2

U. Wasik-Paragraph 4.1.1

A. Filipek-Paragraph 4.1.2

M. Goras-Paragraph 5

(3) All Authors gave final approval of the version to be submitted and any revised version.

\section{Abbreviations}

17-AAG

ABP

$\mathrm{AD}$

AMPAR
17- $N$-allyamino-17-demethoxygeldanamycin

actin-binding proteins

Alzheimer's disease

$\alpha$-amino-3-hydroxy-5-methyl-4-isoxazolepropionic acid receptor 
AMPK

APP

a-SN

ATP

$\mathrm{A} \beta$

BDNF

CacyBP/SIP

cAMP

CBD

Cdk5

CHIP

CK1

CK1

DAPK

DRG

DS

Dyrk1A

E-10

E-2

E-3

EGF

EHD

ERK1/2 kinase

F-actin

FKBB

FTDP-17

Fyn

GABA

G-actin

GCs

Grb2

GSK-3

GTP

HAP1

Hsc70

Hsp70

Hsp90

Hsps

I2

JNK

KHC/KIF5

KIF1

KIF3

KIFs

$\mathrm{KO}$

$\mathrm{Kv}$ adenosine-monophosphate-activated protein kinase amyloid precursor protein $\alpha$-synuclein adenosine triphosphate amyloid beta brain-derived neurotrophic factor calcyclin-binding protein/siah-1-interacting protein cyclic adenosine monophosphate corticobasal degeneration cyclin-dependent kinase 5 chaperone-associated ubiquitin ligase CHIP

casein kinase 1 casein kinase 1

death-associated protein kinase dorsal root ganglia

Down syndrome

dual specificity tyrosine-phosphorylation-regulated kinase 1A

exon 10

exon 2

exon 3

epidermal growth factor

Eps15 homology domain

extracellular signal-regulated kinase $1 / 2$

actin filaments

FK506-binding protein

frontotemporal dementia with parkinsonism linked to chromosome 17

Proto-oncogene tyrosine-protein kinase Fyn

gamma-aminobutyric acid

globular actin monomers

growth cones

growth factor receptor-bound protein 2

glycogen synthase kinase-3

guanosine triphosphate

Huntingtin-associated protein 1

heat shock cognate 70 protein

heat shock protein 70

Heat shock protein 90

heat shock proteins

SET/inhibitor 2

c-Jun amino-terminal kinase

kinesin-1

kinesin-3

kinesin-2

kinesin proteins

knockout

voltage-gated potassium channels 
M3

MAP2

MAPKs

MAPs

MAPT

MARKs

MBD

MF

MPTP

mRNA

mRNP

MT

MTOC

NF

$\mathrm{NFH}$

NFM

NFTs

NGF

NHL

NMDAR

NMR spectroscopy

non-PDPK

N-WASP

PACSIN1/SYNDAPIN1

P-AMPK

$\mathrm{PCH}$

PD

PDC

PDPK

PHFs

PiD

Pin 1

PIP3

p-JNK

PKA

PP1

PP2A

PP2B

PP5

PPI

PPs

Pre-mRNA

PSD-95

PSP

P-tau

Rab5 muscarinic receptor 3

microtubule associated protein

mitogen-activated protein kinases

microtubule-associated-proteins

microtubule-associated protein tau

microtubule-affinity regulating kinases

microtubule binding domain

microfilaments

1-methyl-4-phenyl-1,2,3,6-tetrahydropyridine

messenger ribonucleic acid

messenger ribonucleoprotein

microtubules

microtubule organizing center

neurofilaments

neurofilament heavy

neurofilament medium

neurofibrillary tangles

nerve growth factor

neurofilament light

$N$-methyl-D-aspartate receptor

nuclear magnetic resonance spectroscopy

non-proline-directed protein kinase

neural Wiskott-Aldrich syndrome protein

protein kinase $\mathrm{C}$ and casein kinase substrate in neurons protein 1

activated/phosphorylated AMPK

Pombe Cdc15 homology proteins

Parkinson's disease

parkinsonism dementia complex of Guam

proline-directed protein kinases

paired helical filaments

Pick's disease

peptidyl-prolyl cis-trans isomerase 1

phosphatidylinositol $(3,4,5)$-trisphosphate

phospho-c-Jun amino-terminal kinase

protein kinase $\mathrm{A}$

protein phosphatase 1

protein phosphatase $2 \mathrm{~A}$

calcineurin

protein phosphatase 5

peptidyl-prolyl cis/trans isomerase

protein phosphatases

precursor mRNA

postsynaptic density protein 95

progressive supranuclear palsy

phosphorylated tau

Ras-related protein Rab-5A 


\begin{tabular}{cc} 
Src/cSrc & proto-oncogene tyrosine-protein kinase Src \\
TNAP & tissue-nonspecific alkaline phosphatase \\
TPK & tyrosine protein kinases \\
TPKI & tau protein kinase I \\
TPKII & tau protein kinase II \\
TrkA & neurotrophic tyrosine kinase receptor, type 1 \\
TrkB & neurotrophic tyrosine kinase, receptor, type 2 \\
UPS & ubiquitin proteasome system \\
\hline
\end{tabular}

\section{Conflicts of Interest}

The authors declare no conflict of interest.

\section{References}

1. Grundke-Iqbal, I.; Iqbal, K.; Tung, Y.C.; Quinlan, M.; Wisniewski, H.M.; Binder, L.I. Abnormal phosphorylation of the microtubule-associated protein tau in Alzheimer cytoskeletal pathology. Proc. Natl. Acad. Sci. USA 1986, 83, 4913-4917.

2. Binder, L.I.; Frankfurter, A.; Rebhun, K.I. The distribution of tau in the mammalian central nervous system. J. Cell Biol. 1985, 101, 1371-1378.

3. Hirokawa, N.; Funakoshi, T.; Sato-Harada, R.; Kanai, Y. Selective stabilization of tau in axons and microtubule-associated protein $2 \mathrm{C}$ in cell bodies and dendrites contributes to polarized localization of cytoskeletal proteins in mature neurons. J. Cell Biol. 1996, 132, 667-679.

4. Ittner, L.M.; Ke, Y.D.; Delerue, F.; Bi, M.; Gladbach, A.; van Eersel, J.; Wölfing, H.; Chieng, B.C.; Christie, M.J.; Napier, I.A.; et al. Dendritic function of tau mediates amyloid-beta toxicity in Alzheimer's disease mouse models. Cell 2010, 142, 387-397.

5. Merino-Serrais, P.; Benavides-Piccione, R.; Blazquez-Llorca, L.; Kastanauskaite, A.; Rábano, A.; Avila, J.; DeFelipe, J. The influence of phospho- $\tau$ on dendritic spines of cortical pyramidal neurons in patients with Alzheimer's disease. Brain 2013, 136, 1913-1928.

6. Zempel, H.; Luedtke, J.; Kumar, Y.; Biernat, J.; Dawson, H.; Mandelkow, E.; Mandelkow, E.M. Amyloid- $\beta$ oligomers induce synaptic damage via Tau-dependent microtubule severing by TTLL6 and spastin. EMBO J. 2013, 32, 2920-2937.

7. Goedert, M.; Jakes, R. Expression of separate isoforms of human tau protein: Correlation with the tau pattern in brain and effects on tubulin polymerization. EMBO J. 1990, 9, 4225-4230.

8. Niblock, M.; Gallo, J.M. Tau alternative splicing in familial and sporadic tauopathies. Biochem. Soc. Trans. 2012, 40, 677-680.

9. Majounie, E.; Cross, W.; Newsway, V.; Dillman, A.; Vandrovcova, J.; Morris, C.M.; Nalls, M.A.; Ferrucci, L.; Owen, M.J.; O’Donovan, M.C.; et al. Variation in tau isoform expression in different brain regions and disease states. Neurobiol. Aging 2013, 34, 1922.e7-1922.e12.

10. Rodríguez-Martín, T.; Cuchillo-Ibáñez, I.; Noble, W.; Nyenya, F.; Anderton, B.H.; Hanger, D.P. Tau phosphorylation affects its axonal transport and degradation. Neurobiol. Aging 2013, 34, 2146-2157.

11. Hanger, D.P.; Anderton, B.H.; Noble, W. Tau phosphorylation: The therapeutic challenge for neurodegenerative disease. Trends Mol. Med. 2009, 15, 112-119. 
12. Dixit, R.; Ross, J.L.; Goldman, Y.E.; Holzbaur, E.L. Differential regulation of dynein and kinesin motor proteins by tau. Science 2008, 319, 1086-1089.

13. Götz, J.; Probst, A.; Spillantini, M.G.; Schäfer, T.; Jakes, R.; Bürki, K.; Goedert, M. Somatodendritic localization and hyperphosphorylation of tau protein in transgenic mice expressing the longest human brain tau isoform. EMBO J. 1995, 14, 1304-1313.

14. Santacruz, K.; Lewis, J.; Spires, T.; Paulson, J.; Kotilinek, L.; Ingelsson, M.; Guimaraes, A.; DeTure, M.; Ramsden, M.; McGowan, E.; et al. Tau suppression in a neurodegenerative mouse model improves memory function. Science 2005, 309, 476-481.

15. Müller, W.E.; Eckert, A.; Kurz, C.; Eckert, G.P.; Leuner, K. Mitochondrial dysfunction: Common final pathway in brain aging and Alzheimer's disease-Therapeutic aspects. Mol. Neurobiol. 2010, 41, 159-171.

16. Mondragón-Rodríguez, S.; Perry, G.; Zhu, X.; Moreira, P.I.; Acevedo-Aquino, M.C.; Williams, S. Phosphorylation of tau protein as the link between oxidative stress, mitochondrial dysfunction, and connectivity failure: Implications for Alzheimer's disease. Oxid. Med. Cell. Longev. 2013, 2013, 940603:1-9940603:6.

17. Hoover, B.R.; Reed, M.N.; Su, J.; Penrod, R.D.; Kotilinek, L.A.; Grant, M.K.; Pitstick, R.; Carlson, G.A.; Lanier, L.M.; Yuan, L.L.; et al. Tau mislocalization to dendritic spines mediates synaptic dysfunction independently of neurodegeneration. Neuron 2010, 68, 1067-1081.

18. Prots, I.; Veber, V.; Brey, S.; Campioni, S.; Buder, K.; Riek, R.; Böhm, K.J.; Winner, B. $\alpha$-Synuclein oligomers impair neuronal microtubule-kinesin interplay. J. Biol. Chem. 2013, 288, 21742-21754.

19. Eckert, A.; Nisbet, R.; Grimm, A.; Götz, J. March separate, strike together-Role of phosphorylated TAU in mitochondrial dysfunction in Alzheimer's disease. Biochim. Biophys. Acta 2013, doi:10.1016/j.bbadis.2013.08.013.

20. Andrews-Zwilling,Y.; Bien-Ly, N.; Xu, Q.; Li, G.; Bernardo, A.; Yoon, S.; Zwilling, D.; Yan, T.X.; Chen, L.; Huang, Y. Apolipoprotein E4 causes age- and tau-dependent impairment of GABAergic interneurons, leading to learning and memory deficits in mice. J. Neurosci. 2010, 30, $13707-13717$.

21. Gu, Y.; Oyama, F.; Ihara, Y. Tau is widely expressed in rat tissues. J. Neurochem. 1996, 67, $1235-1244$.

22. Weingarten, M.D.; Lockwood, A.H.; Hwo, S.Y.; Kirschner, M.W. A protein factor essential for microtubule assembly. Proc. Natl. Acad. Sci. USA 1975, 72, 1858-1862.

23. Witman, G.B.; Cleveland, D.W.; Weingarten, M.D.; Kirschner, M.W. Tubulin requires tau for growth onto microtubule initiating sites. Proc. Natl. Acad. Sci. USA 1976, 73, 4070-4074.

24. Andreadis, A. Tau splicing and intricacies of dementia. J. Cell. Physiol. 2012, 227, 1120-1225.

25. Lee, V.M.; Goedert, M.; Trojanowski, J.Q. Neurodegenerative tauopathies. Annu. Rev. Neurosci. 2001, 24, 1121-1159.

26. Tashiro, K.; Hasegawa, M.; Ihara, Y.; Iwatsubo, T. Somatodendritic localization of phosphorylated tau in neonatal and adult rat cerebral cortex. Neuroreport 1997, 8, 2797-2801.

27. Klein, C.; Kramer, E.M.; Cardine, A.M.; Schraven, B.; Brandt, R.; Trotter, J. Process outgrowth of oligodendrocytes is promoted by interaction of fyn kinase with the cytoskeletal protein tau. J. Neurosci. 2002, 22, 698-707. 
28. Jeganathan, S.; von Bergen, M.; Mandelkow, E.M.; Mandelkow, E. The natively unfolded character of Tau and its aggregation to Alzheimer-like paired helical filaments. Biochemistry 2008, 47, 10526-10539.

29. Mukrasch, M.D.; Bibow, S.; Korukottu, J.; Jeganathan, S.; Biernat, J.; Griesinger, C.; Mandelkow, E.; Zweckstetter, M. Structural polymorphism of 441-residue Tau at single residue resolution. PLoS Biol. 2009, 7, e1000034.

30. Sergeant, N.; Bretteville, A.; Hamdane, M.; Caillet-Boudin, M.L.; Grognet, P.; Bombois, S.; Blum, D.; Delacourte, A.; Pasquier, F.; Vanmechelen, E.; et al. Biochemistry of Tau in Alzheimer's disease and related neurological disorders. Exp. Rev. Proteomics 2008, 5, 207-224.

31. Mandelkow, E.M.; Mandelkow, E. Biochemistry and cell biology of tau protein in neurofibrillary degeneration. Cold Spring Harb. Perspect. Med. 2012, 2, a006247.

32. Steiner, B.; Mandelkow, E.M.; Biernat, J.; Gustke, N.; Meyer, H.E.; Schmidt, B.; Mieskes, G.; Soling, H.D.; Drechsel, D.; Kirschner, M.W. Phosphorylation of microtubule-associated protein tau: Identification of the site for $\mathrm{Ca} 2(\mathrm{p})$-calmodulin dependent kinase and relationship with tau phosphorylation in Alzheimer tangles. EMBO J. 1990, 9, 3539-3544.

33. Brandt, R.; Lee, G. Functional organization of microtubule-associated protein tau. Identification of regions which affect microtubule growth, nucleation, and bundle formation in vitro. J. Biol. Chem. 1993, 268, 3414-3419.

34. Sontag, E.; Nunbhakdi-Craig, V.; Lee, G.; Brandt, R.; Kamibayashi, C.; Kuret, J.; White, C.L., 3rd.; Mumby, M.C.; Bloom, G.S. Molecular interactions among protein phosphatase $2 \mathrm{~A}$, tau, and microtubules. Implications for the regulation of tau phosphorylation and the development of tauopathies. J. Biol. Chem. 1999, 274, 25490-25498.

35. Hirokawa, N.; Shiomura, Y.; Okabe, S. Tau proteins: The molecular structure and mode of binding on microtubules. J. Cell Biol. 1988, 107, 1449-1459.

36. Jung, D.; Filliol, D.; Miehe, M.; Rendon, A. Interaction of brain mitochondria with microtubules reconstituted from brain tubulin and MAP2 or TAU. Cell Motil. Cytoskeleton 1993, 24, 245-255.

37. Brandt, R.; Léger, J.; Lee, G. Interaction of tau with the neural plasma membrane mediated by tau's amino-terminal projection domain. J. Cell Biol. 1995, 131, 1327-1340.

38. Al-Bassam, J.; Ozer, R.S.; Safer, D.; Halpain, S.; and Milligan, R.A. MAP2 and tau bind longitudinally along the outer ridges of microtubule protofilaments. J. Cell Biol. 2002, 157, 1187-1196.

39. Sergeant, N.; Delacourte, A.; Buée, L. Tau protein as a differential biomarker of tauopathies. Biochim. Biophys. Acta 2005, 1739, 17915hi.

40. Georgieff, I.S.; Liem, R.K.H.; Couchie, D.; Mavilia, C.; Nunez, J.; Shelanski, M.L. Expression of high molecular weight tau in the central and peripheral nervous systems. J. Cell Sci. 1993, 105, 729-737.

41. Wang, J.Z.; Liu, F. Microtubule-associated protein tau in development, degeneration and protection of neurons. Prog. Neurobiol. 2008, 85, 148-175.

42. Morfini, G.A.; Burns, M.; Binder, L.I.; Kanaan, N.M.; LaPointe, N.; Bosco, D.A.; Brown, R.H., Jr.; Brown, H.; Tiwari, A.; Hayward, L.; et al. Axonal transport defects in neurodegenerative diseases. J. Neurosci. 2009, 29, 12776-12786. 
43. Kosik, K.S. The molecular and cellular biology of tau. Brain Pathol. 1993, 3, 39-43.

44. Jho, Y.S.; Zhulina, E.B.; Kim, M.W.; Pincus, P.A. Monte carlo simulations of tau proteins: Effect of phosphorylation. Biophys. J. 2010, 99, 2387-2397.

45. Fischer, D.; Mukrasch, M.D.; Biernat, J.; Bibow, S.; Blackledge, M.; Griesinger, C.; Mandelkow, E.; Zweckstetter, M. Conformational changes specific for pseudophosphorylation at serine 262 selectively impair binding of tau to microtubules. Biochemistry 2009, 48, 10047-10055.

46. Avila, J. Tau kinases and phosphatases: Commentary. J. Cell. Mol. Med. 2008, 12, 258-259.

47. Dolan, P.J.; Johnson G.V. The role of tau kinases in Alzheimer's disease. Curr. Opin. Drug Discov. Devel. 2010, 13, 595-603.

48. Gustke, N.; Trinczek, B.; Biernat, J.; Mandelkow, E.M.; Mandelkow, E. Domains of tau protein and interactions with microtubules. Biochemistry 1994, 33, 9511-9522.

49. Seitz, A.; Kojima, H.; Oiwa, K.; Mandelkow, E.M.; Song, Y.H.; Mandelkow, E. Single-molecule investigation of the interference between kinesin, tau and MAP2c. EMBO J. 2002, 21, 4896-4905.

50. Mukrasch, M.D.; von Bergen, M.; Biernat, J.; Fischer, D.; Griesinger, C.; Mandelkow, E.; Zweckstetter, M. The "jaws" of the tau-microtubule interaction. J. Biol. Chem. 2007, 282, 12230-12239.

51. Sillen, A.; Barbier, P.; Landrieu, I.; Lefebvre, S.; Wieruszeski, J.M.; Leroy, A.; Peyrot, V.; Lippens, G. NMR investigation of the interaction between the neuronal protein tau and the microtubules. Biochemistry 2007, 46, 3055-3064.

52. Panda, D.; Samuel, J.C.; Massie, M.; Feinstein, S.C.; Wilson, L. Differential regulation of microtubule dynamics by three- and four-repeat tau: Implications for the onset of neurodegenerative disease. Proc. Nat. Acad. Sci. USA 2003, 100, 9548-9553.

53. Santarella, R.A.; Skiniotis, G.; Goldie, K.N.; Tittmann, P.; Gross, H.; Mandelkow, E.M.; Mandelkow, E.; Hoenger, A. Surface-decoration of microtubules by human tau. J. Mol. Biol. 2004, 339, 539-553.

54. Mandell, J.W.; Banker, G.A. A spatial gradient of tau protein phosphorylation in nascent axons. J. Neurosci. 1996, 16, 5727-5740.

55. Yu, J.Z.; Rasenick, M.M. Tau associates with actin in differentiating PC12 cells. FASEB J. 2006, 20, 1452-1461.

56. He, H.J.; Wang, X.S.; Pan, R.; Wang, D.L.; Liu, M.N.; He, R.Q. The proline-rich domain of tau plays a role in interactions with actin. BMC Cell Biol. 2009, 10, 81.

57. Farias, G.A.; Muñoz, J.P.; Garrido, J.; Maccioni, R.B. Tubulin, actin, and tau protein interactions and the study of their macromolecular assemblies. J. Cell. Biochem. 2002, 85, 315-324.

58. Sharma, V.M.; Litersky, J.M.; Bhaskar, K.; Lee, G. Tau impacts on growth-factor-stimulated actin remodeling. J. Cell Sci. 2007, 120, 748-757.

59. Niewiadomska, G.; Baksalerska-Pazera, M.; Riedel, G. Altered cellular distribution of phospho-tau proteins coincides with impaired retrograde axonal transport in neurons of aged rats. Ann. N. Y. Acad. Sci. 2005, 1048, 287-295.

60. Niewiadomska, G.; Baksalerska-Pazera, M.; Lenarcik, I.; Riedel, G.J, Compartmental protein expression of Tau, GSK-3beta and TrkA in cholinergic neurons of aged rats. J. Neural Transm. 2006, 113, 1733-1746. 
61. Leugers, C.J.; Lee, G. Tau potentiates nerve growth factor-induced mitogen-activated protein kinase signaling and neurite initiation without a requirement for microtubule binding. J. Biol. Chem. 2010, 285, 19125-19134.

62. Reynolds, C.H.; Garwood, C.J.; Wray, S.; Price, C.; Kellie, S.; Perera, T.; Zvelebil, M.; Yang, A.; Sheppard, P.W.; Varndell, I.M.; et al. Phosphorylation regulates tau interactions with Src homology 3 domains of phosphatidylinositol 3-kinase, phospholipase Cgamma1, Grb2, and Src family kinases. J. Biol. Chem. 2008, 283, 18177-18186.

63. Lee, G.; Thangvel, R.; Sharma, V.M.; Litersky, J.M.; Bhaskar, K.; Fang, S.M.; Do, L.H.; Andreadis, A.; van Hoesen, G.; Ksiezak-Reding, H. Phosphorylation of tau by fyn: Implications for Alzheimer's disease. J. Neurosci. 2004, 4, 2304-2312.

64. Miyasaka, T.; Watanabe, A.; Saito, Y.; Murayama, S.; Mann, D.M.; Yamazaki, M.; Ravid, R.; Morishima-Kawashima, M.; Nagashima, K.; Ihara, Y. Visualization of newly deposited tau in neurofibrillary tangles and neuropil threads. J. Neuropathol. Exp. Neurol. 2005, 64, 665-674.

65. Ledesma, M.D.; Bonay, P.; Colaço, C.; Avila, J. Analysis of microtubule-associated protein tau glycation in paired helical filaments. J. Biol. Chem. 1994, 269, 21614-21619.

66. Reyes, J.F.; Reynolds, M.R.; Horowitz, P.M.; Fu, Y.; Guillozet-Bongaarts, A.L.; Berry, R.; Binder, L.I. A possible link between astrocyte activation and tau nitration in Alzheimer's disease. Neurobiol. Dis. 2008, 31, 198-208.

67. Arnold, C.S.; Johnson, G.V.; Cole, R.N.; Dong, D.L.; Lee, M.; Hart, G.W. The microtubule-associated protein tau is extensiveely modified with O-linked $N$-acetylglucosamine. J. Biol. Chem. 1996, 271, 28741-28744.

68. Cohen, T.J.; Guo, J.L.; Hurtado, D.E.; Kwong, L.K.; Mills, I.P.; Trojanowski, J.Q.; Lee, V.M. The acetylation of tau inhibits its function and promotes pathological tau aggregation. Nat. Commun. 2011, 2, 252.

69. Landino, L.M.; Skreslet, T.E.; Alston, J.A. Cysteine oxidation of tau and microtubule-associated protein- 2 by peroxynitrite: Modulation of microtubule assembly kinetics by the thioredoxin reductase system. J. Biol. Chem. 2004, 279, 35101-35105.

70. Wilhelmus, M.M.; Grunberg, S.C.; Bol, J.G.; van Dam, A.M.; Hoozemans, J.J.; Rozemuller, A.J.; Drukarch, B. Transglutaminases and transglutaminase-catalyzed cross-links colocalize with the pathological lesions in Alzheimer's disease brain. Brain Pathol. 2009, 19, $612-622$.

71. Dorval, V.; Fraser P.E. Small ubiquitin-like modifier (SUMO) modification of natively unfolded proteins tau and alpha-synuclein. J. Biol. Chem. 2006, 281, 9919-9924.

72. Cripps, D.; Thomas, S.N.; Jeng, Y.; Yang, F.; Davies, P.; Yang, A.J. Alzheimer disease-specific conformation of hyperphosphorylated paired helical filament-Tau is polyubiquitinated through Lys-48, Lys-11, and Lys-6 ubiquitin conjugation. J. Biol. Chem. 2006, 281, 10825-10838.

73. Mondragón-Rodríguez, S.; Basurto-Islas, G.; Binder, L.I.; García-Sierra, F. Conformational changes and cleavage; are these responsible for the tau aggregation in Alzheimer's disease? Futur. Neurol. 2009, 4, 39-53. 
74. Bhat, R.V.; Shanley, J.; Correll, M.P.; Fieles, W.E.; Keith, R.A.; Scott, C.W.; Lee, C.M. Regulation and localization of tyrosine 216 phosphorylation of glycogen synthase kinase-3beta in cellular and animal models of neuronal degeneration. Proc. Natl. Acad. Sci. USA 2000, 26, 11074-11079.

75. Wang, Q.M.; Fiol, C.J.; DePaoli-Roach, A.A.; Roach, P.J. Glycogen synthase kinase-3 beta is a dual specificity kinase differentially regulated by tyrosine and serine/threonine phosphorylation. J. Biol. Chem. 1994, 269, 14566-14574.

76. Giese, K.P. GSK-3: A key player in neurodegeneration and memory. IUBMB Life 2009, 61, 516-521.

77. Ishiguro, K.; Shiratsuchi, A.; Sato, S.; Omori, A.; Arioka, M.; Kobayashi, S.; Uchida, T.; Imahori, K. Glycogen synthase kinase 3 beta is identical to tau protein kinase I generating several epitopes of paired helical filaments. FEBS Lett. 1993, 325, 167-172.

78. Lovestone, S.; Reynolds, C.H.; Latimer, D.; Davis, D.R.; Anderton, B.H.; Gallo, J.M.; Hanger, D.; Mulot, S.; Marquardt, B.; Stabel, S.; et al. Alzheimer disease-like phosphorylation of the microtubule-associated protein tau by glycogen synthase kinase-3 in transfected mammalian cells. Curr. Biol. 1994, 4, 1077-1086.

79. Reynolds, C.H.; Betts, J.C.; Blackstock, W.P.; Nebreda, A.R.; Anderton, B.H. Phosphorylation sites on tau identified by nanoelectrospray mass spectrometry: Differences in vitro between the mitogen-activated protein kinases ERK2, c-Jun $N$-terminal kinase and P38, and glycogen synthase kinase-3beta. J. Neurochem. 2000, 74, 1587-1595.

80. Pei, J.J.; Tanaka, T.; Tung, Y.C.; Braak, E.; Iqbal, K.; Grundke-Iqbal, I. Distribution, levels, and activity of glycogen synthase kinase-3 in the Alzheimer disease brain. J. Neuropathol. Exp. Neurol. 1997, 56, 70-78.

81. Leroy, K.; Boutajangout, A.; Authelet, M.; Woodgett, J.R.; Anderton, B.H.; Brion, J.P. The active form of glycogen synthase kinase-3 $\beta$ is associated with granulovacuolar degeneration in neurons in Alzheimers's disease. Acta Neuropathol. 2002, 103, 91-99.

82. Yamaguchi, H.; Ishiguro, K.; Uchida, T.; Takashima, A.; Lemere, C.A.; Imahori, K. Preferential labeling of Alzheimer neurofibrillary tangles with antisera for tau protein kinase (TPK) I/glycogen synthase kinase-3 beta and cyclin-dependent kinase 5, a component of TPK II. Acta Neuropathol. 1996, 92, 232-241.

83. Alvarez, G.; Munoz-Montano, J.R.; Satrustegui, J.; Avila, J.; Bogonez, E.; Diaz-Nido, J. Lithium protects cultured neurons against beta-amyloid-induced neurodegeneration. FEBS Lett. 1999, 453, 260-264.

84. Tan, W.F.; Cao, X.Z.; Wang, J.K.; Lv, H.W.; Wu, B.Y. Protective effects of lithium treatment for spatial memory deficits induced by tau hyperphosphorylation in splenectomized rats. Clin. Exp. Pharmacol. Physiol. 2010, 37, 1010-1015.

85. Biernat. J.; Gustke, N.; Drewes, G.; Mandelkow, E.M.; Mandelkow, E. Phosphorylation of Ser262 strongly reduces binding of tau to microtubules: Distinction between PHF-like immunoreactivity and microtubule binding. Neuron 1993, 11, 153-156.

86. Muntané, G.; Dalfó, E.; Martinez, A.; Ferrer, I. Phosphorylation of tau and alpha-synuclein in synaptic-enriched fractions of the frontal cortex in Alzheimer's disease, and in Parkinson's disease and related alpha-synucleinopathies. Neuroscience 2008, 152, 913-923. 
87. Gaig, C.; Ezquerra, M.; Marti, M.J.; Valldeoriola, F.; Muñoz, E.; Lladó, A.; Rey, M.J.; Cardozo, A.; Molinuevo, J.L.; Tolosa, E. Screening for the LRRK2 G2019S and codon-1441 mutations in a pathological series of Parkinsonian syndromes and frontotemporal lobar degeneration. J. Neurol. Sci. 2008, 270, 94e8.

88. Wang, Y.; Liu, W.; He, X.; Zhou, F. Parkinson's Disease-Associated Dj-1 Mutations increase

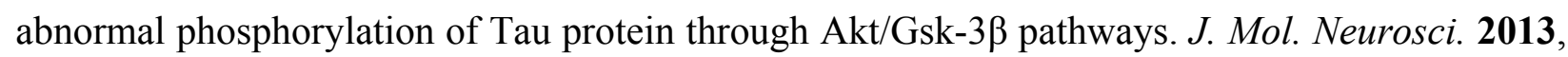
51, 911-918.

89. Noble, W.; Planel, E.; Zehr, C.; Olm, V.; Meyerson, J.; Suleman, F.; Gaynor, K.; Wang, L.; LaFrancois, J.; Feinstein, B.; et al. Inhibition of glycogen synthase kinase-3 by lithium correlates with reduced tauopathy and degeneration in vivo. Proc. Natl. Acad. Sci. USA 2005, 102, 6990-6995.

90. Köhler, C.; Dinekov, M.; Götz, J. Active glycogen synthase kinase-3 and tau pathology-related tyrosine phosphorylation in pR5 human tau transgenic mice. Neurobiol. Aging 2013, 34, 1369-1379.

91. Dhavan, R.; Tsai, L.H. A decade of CDK5. Nat. Rev. Mol. Cell. Biol. 2001, 2, 749-759.

92. Lee, M.S.; Kwon, Y.T.; Li, M.; Peng, J.; Friedlander, R.M.; Tsai, L.H. Neurotoxicity induces cleavage of p35 to p25 by calpain. Nature 2000, 405, 360-364.

93. Noble, W.; Olm, V.; Takata, K.; Casey, E.; Mary, O.; Meyerson, J.; Gaynor, K.; LaFrancois, J.; Wang, L.; Kondo, T.; et al. Cdk5 is a key factor in tau aggregation and tangle formation in vivo. Neuron 2003, 38, 555-565.

94. Cruz, J.C.; Tseng, H.C.; Goldman, J.A.; Shih, H.; Tsai, L.H. Aberrant Cdk5 activation by p25 triggers pathological events leading to neurodegeneration and neurofibrillary tangles. Neuron 2003, 30, 471-83.

95. Patrick, G.N.; Zukerberg, L.; Nikolic, M.; de la Monte, S.; Dikkes, P.; Tsai, L.H. Conversion of p35 to p25 deregulates Cdk5 activity and promotes neurodegeneration. Nature 1999, 402, 615-622.

96. Piedrahita, D.; Hernández, I.; López-Tobón, A.; Fedorov, D.; Obara, B.; Manjunath, B.S.; Boudreau, R.L.; Davidson, B.; Laferla, F.; Gallego-Gómez, J.C.; et al. Silencing of CDK5 reduces neurofibrillary tangles in transgenic Alzheimer mice. J. Neurosci. 2010, 30, 13966-13976.

97. Li, T.; Hawkes, C.; Qureshi, H.Y.; Kar, S.; Paudel, H.K. Cyclin-dependent protein kinase 5 primes microtubule-associated protein tau site-specifically for glycogen synthase kinase 3 beta. Biochemistry 2006, 45, 3134-3145.

98. Liou, Y.C.; Sun, A.; Ryo, A.; Zhou, X.Z.; Yu, Z.X.; Huang, H.K.; Uchida, T.; Bronson, R.; Bing, G.; Li, X.; et al. Role of the prolyl isomerase Pin1 in protecting against age-dependent neurodegeneration. Nature 2003, 424, 556-61.

99. Yotsumoto, K.; Saito, T.; Asada, A.; Oikawa, T.; Kimura, T.; Uchida, C.; Ishiguro, K.; Uchida, T.; Hasegawa, M.; Hisanaga, S. Effect of Pin1 or microtubule binding on dephosphorylation of FTDP-17 mutant Tau. J. Biol. Chem. 2009, 284, 16840-16847.

100. Kimura, T.; Tsutsumi, K.; Taoka, M.; Saito, T.; Masuda-Suzukake, M.; Ishiguro, K.; Plattner, F.; Uchida, T.; Isobe, T.; Hasegawa, M.; et al. Isomerase Pin1 stimulates dephosphorylation of tau protein at cyclin-dependent kinase (Cdk5)-dependent Alzheimer phosphorylation sites. J. Biol. Chem. 2013, 288, 7968-7977. 
101. Ferrer, I.; Blanco, R.; Carmona, M.; Puig, B. Phosphorylated mitogen-activated protein kinase (MAPK/ERK-P), protein kinase of $38 \mathrm{kDa}$ (p38-P), stress-activated protein kinase (SAPK/JNK-P), and calcium/calmodulin-dependent kinase II (CaM kinase II) are differentially expressed in tau deposits in neurons and glial cells in tauopathies. J. Neural Transm. 2001, 108, 1397-1415.

102. Mohit, A.A.; Martin, J.H.; Miller, C.A. p493F12 kinase: A novel MAP kinase expressed in a subset of neurons in the human nervous system. Neuron 1995, 14, 67-78.

103. Zhu, X.; Raina, A.K.; Rottkamp, C.A.; Aliev, G.; Perry, G.; Boux, H.; Smith, M.A. Activation and redistribution of c-jun $N$-terminal kinase/stress activated protein kinase in degenerating neurons in Alzheimer disease. J. Neurochem. 2001, 76, 435-441.

104. Knippschild, U.; Gocht, A.; Wolff, S.; Huber, N.; Löhler, J.; Stöter, M. The casein kinase 1 family: Participation in multiple cellular processes in eukaryotes. Cell. Signal. 2005, 17, 675-689.

105. Singh, T.J.; Grundke-Iqbal, I.; Iqbal, K. Phosphorylation of tau protein by casein kinase-1 converts it to an abnormal Alzheimer-like state. J. Neurochem. 1995, 64, 1420-1423.

106. Kuret, J.; Johnson, G.S.; Cha, D.; Christenson, E.R.; DeMaggio, A.J.; Hoekstra, M.F. Casein kinase 1 is tightly associated with paired-helical filaments isolated from Alzheimer disease brain. J. Neurochem. 1997, 69, 2506-2515.

107. Li, G.; Yin, H.; Kuret, J. Casein kinase 1 delta phosphorylates tau and disrupts its binding to microtubules. J. Biol. Chem. 2004, 279, 15938-15945.

108. Schwab, C.; DeMaggio, A.J.; Ghoshal, N.; Binder, L.I.; Kuret, J.; McGeer, P.L. Casein kinase 1 delta is associated with pathological accumulation of tau in several neurodegenerative diseases. Neurobiol. Aging 2000, 21, 503-510.

109. Yasojima, K.; Kuret, J.; DeMaggio, A.J.; McGeer, E.; McGeer, P.L. Casein kinase 1 delta mRNA is upregulated in Alzheimer disease brain. Brain Res. 2000, 865, 116-120.

110. Ferrer, I.; Barrachina, M.; Puig, B.; Martínez de Lagrán, M.; Martí, E.; Avila, J.; Dierssen, M. Constitutive Dyrk1A is abnormally expressed in Alzheimer disease, Down syndrome, Pick disease, and related transgenic models. Neurobiol. Dis. 2005, 20, 392-400.

111. Liu, F.; Liang, Z.; Wegiel, J.; Hwang, Y.W.; Iqbal, K.; Grundke-Iqbal, I.; Ramakrishna, N.; Gong, C.X. Overexpression of Dyrk1A contributes to neurofibrillary degeneration in Down syndrome. FASEB J. 2008, 22, 3224-3233.

112. Ryoo, S.R.; Jeong, H.K.; Radnaabazar, C.; Yoo, J.J.; Cho, H.J.; Lee, H.W.; Kim, I.S.; Cheon, Y.H.; Ahn, Y.S.; Chung, S.H.; et al. DYRK1A-mediated hyperphosphorylation of Tau. A functional link between Down syndrome and Alzheimer disease. J. Biol. Chem. 2007, 282, 34850-34857.

113. Wegiel, J.; Kaczmarski, W.; Barua, M.; Kuchna, I.; Nowicki, K.; Wang, K.C.; Wegiel, J.; Yang, S.M.; Frackowiak, J.; Mazur-Kolecka, B.; et al. Link between DYRK1A overexpression and several-fold enhancement of neurofibrillary degeneration with 3-repeat tau protein in Down syndrome. J. Neuropathol. Exp. Neurol. 2011, 70, 36-50.

114. Vingtdeux, V.; Davies, P.; Dickson, D.W.; Marambaud, P. AMPK is abnormally activated in tangle- and pre-tangle-bearing neurons in Alzheimer disease and other tauopathies. Acta Neuropathol. 2011, 121, 337-349. 
115. Thornton, C.; Bright, N.J.; Sastre, M.; Muckett, P.J.; Carling, D. AMP-activated protein kinase (AMPK) is a tau kinase, activated in response to amyloid $\beta$-peptide exposure. Biochem. J. 2011, 434, 503-512.

116. Timm, T.; Marx, A.; Panneerselvam, S.; Mandelkow, E.; Mandelkow, E.M. Structure and regulation of MARK, a kinase involved in abnormal phosphorylation of Tau protein. BMC Neurosci. 2008, 2, S9.

117. Chin, J.Y.; Knowles, R.B.; Schneider, A.; Drewes, G.; Mandelkow, E.M.; Hyman, B.T. Microtubule-affinity regulating kinase (MARK) is tightly associated with neurofibrillary tangles in Alzheimer brain: A fluorescence resonance energy transfer study. J. Neuropathol. Exp. Neurol. 2000, 59, 966-971.

118. Gustke, N.; Steiner, B.; Mandelkow, E.M.; Biernat, J.; Meyer, H.E.; Goedert, M.; Mandelkow, E. The Alzheimer-like phosphorylation of tau protein reduces microtubule binding and involves Ser-Pro and Thr-Pro motifs. FEBS Lett. 1992, 307, 199-205.

119. Augustinack, J.C.; Sanders, J.L.; Tsai, L.H.; Hyman, B.T. Colocalization and fluorescence resonance energy transfer between cdk5 and AT8 suggests a close association in pre-neurofibrillary tangles and neurofibrillary tangles. J. Neuropathol. Exp. Neurol. 2002, 61, 557-564.

120. Augustinack, J.C.; Schneider, A.; Mandelkow, E.M.; Hyman, B.T. Specific tau phosphorylation sites correlate with severity of neuronal cytopathology in Alzheimer's disease. Acta Neuropathol. 2002, 103, 26-35.

121. Mocanu, M.M.; Nissen, A.; Eckermann, K.; Khlistunova, I.; Biernat, J.; Drexler, D.; Petrova, O.; Schönig, K.; Bujard, H.; Mandelkow, E.; et al. The potential for beta-structure in the repeat domain of tau protein determines aggregation, synaptic decay, neuronal loss, and coassembly with endogenous Tau in inducible mouse models of tauopathy. J. Neurosci. 2008, 28, 737-748.

122. Gu, G.J.; Lund, H.; Wu, D.; Blokzijl, A.; Classon, C.; von Euler, G.; Landegren, U.; Sunnemark, D.; Kamali-Moghaddam, M. Role of individual MARK isoforms in phosphorylation of tau at Ser262 in Alzheimer disease. Neuromol. Med. 2013, 15, 458-469.

123. Wu, P.R.; Tsai, P.I.; Chen, G.C.; Chou, H.J.; Huang, Y.P.; Chen, Y.H.; Lin, M.Y.; Kimchi, A.; Chien, C.T.; Chen, R.H. DAPK activates MARK1/2 to regulate microtubule assembly, neuronal differentiation, and tau toxicity. Cell Death Differ. 2011, 18, 1507-1520.

124. Sun, L.; Wang, X.; Liu, S.; Wang, Q.; Wang, J.; Bennecib, M.; Gong, C.X.; Sengupta, A.; Grundke-Iqbal, I.; Iqbal, K. Bilateral injection of isoproterenol into hippocampus induces Alzheimer-like hyperphosphorylation of tau and spatial memory deficit in rat. FEBS Lett. 2005, 579, 251-258.

125. Liu, F.; Liang, Z.; Shi, J.; Yin, D.; El-Akkad, E.; Grundke-Iqbal, I.; Iqbal, K.; Gong, C.X. PKA modulates GSK-3beta- and cdk5-catalyzed phosphorylation of tau in site- and kinase-specific manners. FEBS Lett. 2006, 580, 6269-6274.

126. Liu, F.; Li, B.; Tung, E.J.; Grundke-Iqbal, I.; Iqbal, K.; Gong, C.X. Site-specific effects of tau phosphorylation on its microtubule assembly activity and self-aggregation. Eur. J. Neurosci. 2007, 26, 3429-3436.

127. Liu, S.J.; Zhang, J.Y.; Li, H.L.; Fang, Z.Y., Wang, Q.; Deng, H.M.; Gong, C.X.; Grundke-Iqbal, I.; Iqbal, K.; Wang, J.Z. Tau becomes a more favorable substrate for GSK-3 when it is prephosphorylated by PKA in rat brain. J. Biol. Chem. 2004, 279, 50078-50088. 
128. Arioka, M.; Tsukamoto, M.; Ishiguro, K.; Kato, R.; Sato, K.; Imahori, K.; Uchida, T. Tau protein kinase II is involved in the regulation of the normal phosphorylation state of tau protein. J. Neurochem. 1993, 60, 461-468.

129. Imahori, K.; Hoshi, M.; Ishiguro, K.; Sato, K.; Takahashi, M.; Shiurba. R.; Yamaguchi. H.; Takashima, A.; Uchida, T. Possible role of tau protein kinases in pathogenesis of Alzheimer disease. Neurobiol. Aging 1998, 19, S93-S98.

130. Rank, K.B.; Pauley, A.M.; Bhattacharya, K.; Wang, Z.; Evans, D.B.; Fleck, T.J.; Johnston, J.A.; Sharma, S.K. Direct interaction of soluble human recombinant tau protein with Abeta 1-42 results in tau aggregation and hyperphosphorylation by tau protein kinase II. FEBS Lett. 2002, $514,263-268$.

131. Takashima, A.; Honda, T.; Yasutake, K.; Michel, G.; Murayama, O.; Murayama, M.; Ishiguro, K.; Yamaguchi, H. Activation of tau protein kinase I/glycogen synthase kinase-3beta by amyloid beta peptide (25-35) enhances phosphorylation of tau in hippocampal neurons. Neurosci. Res. 1998, 31, 317-323.

132. Braithwaite, S.P.; Stock, J.B.; Lombroso, P.J.; Nairn, A.C. Protein phosphatases and Alzheimer's disease. Prog. Mol. Biol. Transl. Sci. 2012, 106, 343-379.

133. Garver, T.D.; Kincaid, R.L.; Conn, R.A.; Billingsley, M.L. Reduction of calcineurin activity in brain by antisense oligonucleotides leads to persistent phosphorylation of tau protein at Thr181 and Thr231. Mol. Pharmacol. 1999, 55, 632-641.

134. Rahman, A.; Grundke-Iqbal, I.; Iqbal, K. PP2B isolated from human brain preferentially dephosphorylates Ser-262 and Ser-396 of the Alzheimer disease abnormally hyperphosphorylated tau. J. Neural Transm. 2006, 113, 219-230.

135. Qian, W.; Yin, X.; Hu, W.; Sh, J.; Gu, J.; Grundke-Iqbal, I.; Iqbal, K.; Gong, C.X.; Liu, F. Activation of protein phosphatase 2B and hyperphosphorylation of Tau in Alzheimer's disease. J. Alzheimers Dis. 2011, 23, 617-627.

136. Kim, Y.; Lee, Y.I.; Seo, M.; Kim, S.Y.; Lee, J.E.; Youn, H.D.; Kim, Y.S.; Juhnn, Y.S. Calcineurin dephosphorylates glycogen synthase kinase-3 beta at serine-9 in neuroblast-derived cells. J. Neurochem. 2009, 111, 344-354.

137. Iqbal, K.; Alonso, A.C.; Chen, S.; Chohan, M.O.; El-Akkad, E.; Gong, C.X., Khatoon, S.; Li, B.; Liu, F.; Rahman, A.; et al. Tau pathology in Alzheimer disease and other tauopathies. Biochim. Biophys. Acta 2005, 1739, 198-210.

138. Landrieu, I.; Smet-Nocca, C.; Amniai, L.; Louis, J.V.; Wieruszeski, J.M.; Goris, J.; Janssens, V.; Lippens, G. Molecular implication of PP2A and Pin1 in the Alzheimer's disease specific hyperphosphorylation of Tau. PLoS One 2011, 6, e21521.

139. Merrick, S.E.; Demoise, D.C.; Lee, V.M. Site-specific dephosphorylation of tau protein at Ser202/Thr205 in response to microtubule depolymerization in cultured human neurons involves protein phosphatase 2A. J. Biol. Chem. 1996, 271, 5589-5594.

140. Sontag, J.M.; Nunbhakdi-Craig, V.; White, C.L., 3rd; Halpain, S.; Sontag, E. The protein phosphatase PP2A/Balpha binds to the microtubule-associated proteins Tau and MAP2 at a motif also recognized by the kinase Fyn: Implications for tauopathies. J. Biol. Chem. 2012, 287, 14984-14993. 
141. Tanimukai, H.; Grundke-Iqbal, I.; Iqbal, K. Up-regulation of inhibitors of protein phosphatase-2A in Alzheimer's disease. Am. J. Pathol. 2005, 166, 1761-1771.

142. Gharbi-Ayachi, A.; Labbe, J.C.; Burgess, A.; Vigneron, S.; Strub, J.M.; Brioudes, E.; van-Dorsselaer, A.; Castro, A.; Lorca, T. The substrate of Greatwall kinase, Arpp 19, controls mitosis by inhibiting protein phosphatase 2A. Science 2010, 330, 1673-1677.

143. Mochida, S.; Maslen, S.L.; Skehel, M.; Hunt, T. Greatwall phosphorylates an inhibitor of protein phosphatase 2A that is essential for mitosis. Science 2010, 330, 1670-1673.

144. Bollen, M. Combinatorial control of protein phosphatase-1. Trends Biochem. Sci. 2001, 26, 426-431.

145. Rahman, A.; Grundke-Iqbal, I.; Iqbal, K. Phosphothreonine-212 of Alzheimer abnormally hyperphosphorylated tau is a preferred substrate of protein phosphatase-1. Neurochem. Res. 2005, 30, 277-287.

146. Lapointe, N.E.; Morfini, G.; Pigino, G.; Gaisina, I.N.; Kozikowski, A.P.; Binder, L.I.; Brady, S.T. The amino terminus of tau inhibits kinesin-dependent axonal transport: Implications for filament toxicity. J. Neurosci. Res. 2009, 87, 440-451.

147. Kanaan, N.M.; Morfini, G.A.; Lapointe, N.E.; Pigino, G.F.; Patterson, K.R.; Song, Y.; Andreadis, A.; Fu, Y.; Brady, S.T.; Binder, L.I. Pathogenic forms of tau inhibit kinesin-dependent axonal transport through a mechanism involving activation of axonal phosphotransferases. J. Neurosci. 2011, 31, 9858-9868.

148. Liu, F.; Iqbal, K.; Grundke-Iqbal, I.; Rossie, S.; Gong, C.X. Dephosphorylation of tau by protein phosphatase 5: Impairment in Alzheimer's disease. J. Biol. Chem. 2005, 280, 1790-1796.

149. Yamaguchi, F.; Umeda, Y.; Shimamoto, S.; Tsuchiya, M.; Tokumitsu, H.; Tokuda, M.; Kobayashi, R. S100 Proteins Modulate Protein Phosphatase 5 Function: A link between $\mathrm{Ca}^{2+}$ signal transduction and protein dephosphorylation. J. Biol. Chem. 2012, 287, 13787-13798.

150. Fedrizzi, L.; Carafoli, E. $\mathrm{Ca}^{2+}$ dysfunction in neurodegenerative disorders: Alzheimer's disease. Biofactors 2011, 37, 189-196.

151. Wasik, U.; Schneider, G.; Mietelska-Porowska, A.; Mazurkiewicz, M.; Fabczak, H.; Weis, S.; Zabke, C.; Harrington, C.R.; Filipek, A.; Niewiadomska, G. Calcyclin binding protein and Siah-1 interacting protein in Alzheimer's disease pathology: Neuronal localization and possible function. Neurobiol. Aging 2013, 34, 1380-1388.

152. Kilanczyk, E.; Filipek, S.; Filipek, A. ERK1/2 is dephosphorylated by a novel phosphataseCacyBP/SIP. Biochem. Biophys. Res. Commun. 2011, 404, 179-183.

153. Diaz-Hernandez, M.; Gomez-Ramos, A.; Rubio, A.; Gomez-Villafuertes, R.; Naranjo, J.R.; Miras-Portugal, M.T.; Avila, J. Tissue-nonspecific alkaline phosphatase promotes the neurotoxicity effect of extracellular tau. J. Biol. Chem. 2010, 285, 32539-32548.

154. Necula, M.; Kuret, J. Pseudophosphorylation and glycation of tau protein enhance but do not trigger fibrillization in vitro. J. Biol. Chem. 2004, 279, 49694- 49703.

155. Smet-Nocca, C.; Broncel, M.; Wieruszeski, J.M.; Tokarski, C.; Hanoulle, X.; Leroy, A.; Landrieu, I.; Rolando, C.; Lippensa, G.; Hackenberger, C.P.R. Identification of O-GlcNAc sites within peptides of the Tau protein and their impact on phosphorylation. Mol. BioSyst. 2011, 7, $1420-1429$. 
156. Yuzwa, S.A.; Macauley, M.S.; Heinonen, J.E.; Shan, X.; Dennis, R.J.; He, Y.; Whitworth, G.E.; Stubbs, K.A.; McEachern, E.J.; Davies, G.J.; et al. A potent mechanism-inspired O-GlcNAcase inhibitor that blocks phosphorylation of tau in vivo. Nat. Chem. Biol. 2008, 4, 483-490.

157. Borghgraef, P.; Menuet, C.; Theunis, C.; Louis, J.V.; Devijver, H.; Maurin, H.; Smet-Nocca, C.; Lippens, G.; Hilaire, G.; Gijsen H.; et al. Increasing brain protein O-GlcNAc-ylation mitigates breathing defects and mortality of Tau.P301L mice. PLoS One 2013, doi:10.1371/journal.pone.0084442.

158. Liu, F.; Shi, J.; Tanimukai, H.; Gu, J.; Grundke-Iqbal, I.; Iqbal, K.; Gong, C.X. Reduced $O$-GlcNAcylation links lower brain glucose metabolism and tau pathology in Alzheimer's disease. Brain 2009, 132, 1820-1832.

159. Takahashi, M.; Tsujioka, Y.; Yamada, T.; Tsuboi, Y.; Okada, H.; Yamamoto, T.; Liposits, Z. Glycosylation of microtubule-associated protein tau in Alzheimer's disease brain. Acta Neuropathol. 1999, 7, 635-641.

160. Ledesma, M.D.; Medina, M.; Avila, J.; The in vitro formation of recombinant tau polymers: Effect of phosphorylation and glycation. Mol. Chem. Neuropathol. 1996, 27, 249-258.

161. Su, B.; Wang, X.; Lee, H.G.; Tabaton, M.; Perry, G.; Smith, M.A.; Zhu, X. Chronic oxidative stress causes increased tau phosphorylation in M17 neuroblastoma cells. Neurosci. Lett. 2010, 468, 267-271.

162. Zhang, Y.J.; Xu, Y.F.; Liu, Y.H.; Yin, J.; Li, H.L.; Wang, Q.; Wang, J.Z. Peroxynitrite induces Alzheimer-like tau modifications and accumulation in rat brain and its underlying mechanisms. FASEB J. 2006, 20, 1431-1442.

163. Singer, S.M.; Zainelli, G.M.; Norlund, M.A.; Lee, J.M.; Muma, N.A. Transglutaminase bonds in neurofibrillary tangles and paired helical filament tau early in Alzheimer's disease. Neurochem. Int. 2002, 40, 17-30.

164. Bancher, C.; Grundke-Iqbal, I.; Iqbal, K.; Fried, V.A.; Smith, H.T.; Wisniewski, H.M. Abnormal phosphorylation of tau precedes ubiquitination in neurofibrillary pathology of Alzheimer disease. Brain Res. 1991, 539, 11-18.

165. Riederer, I.M.; Schiffrin, M.; Kovari, E.; Bouras, C.; Riederer, B.M. Ubiquitination and cysteine nitrosylation during aging and Alzheimer's disease. Brain Res. Bull. 2009, 80, 233-241.

166. Takahashi, K.; Ishida, M.; Komano, H.; Takahashi, H. SUMO-1 immunoreactivity co-localizes with phospho-Tau in APP transgenic mice but not in mutant Tau transgenic mice. Neurosci. Lett. 2008, 441, 90-93.

167. Newman, M.; Musgrave, I.F.; Lardelli, M. Alzheimer disease: Amyloidogenesis, the presenilins and animal models. Biochim. Biophys. Acta 2007, 1772, 285-297.

168. Amadoro, G.; Corsetti, V.; Ciotti, M.T.; Florenzano, F.; Capsoni, S.; Amato, G.; Calissano, P. Endogenous A $\beta$ causes cell death via early tau phosphorylation. Neurobiol. Aging 2011, 32, 969-990.

169. Hardy, J.; Selkoe, D.J. The amyloid hypothesis of Alzheimer's disease: Progress and problems on the road to therapeutics. Science 2002, 297, 353-356.

170. Ittner, L.M.; Götz, J. Amyloid- $\beta$ and tau-A toxic pas de deux in Alzheimer's disease. Nat. Rev. Neurosci. 2011, 12, 67-72. 
171. Vossel, K.A.; Zhang, K.; Brodbeck, J.; Daub, A.C.; Sharma, P.; Finkbeiner, S.; Cui, B.; Mucke, L. Tau reduction prevents A $\beta$-induced defects in axonal transport. Science 2010, 330, 198.

172. Fein, J.A.; Sokolow, S.; Miller, C.A.; Vinters, H.V.; Yang, F.; Cole, G.M.; Gylys, K.H. Co-localization of amyloid beta and tau pathology in Alzheimer's disease synaptosomes. Am. J. Pathol. 2008, 172, 1683-1692.

173. Takahashi, R.H.; Capetillo-Zarate, E.; Lin, M.T.; Milner, T.A.; Gouras, G.K. Co-occurrence of Alzheimer's disease beta-amyloid and tau pathologies at synapses. Neurobiol. Aging 2010, 31, 1145-1152.

174. Du, H.; Guo, L.; Yan, S.; Sosunov, A.A.; McKhann, G.M.; Yan, S.S. Early deficits in synaptic mitochondria in an Alzheimer's disease mouse model, Proc. Natl. Acad. Sci. USA 2010, 107, 18670-18675.

175. Hamdane, M.; Dourlen, P.; Bretteville, A.; Sambo, A.V.; Ferreira, S.; Ando, K.; Kerdraon, O.; Bégard, S.; Geay, L.; Lippens, G.; et al. Pin1 allows for differential Tau dephosphorylation in neuronal cells. Mol. Cell. Neurosci. 2006, 1-2, 155-160.

176. Lim, J.; Balastik, M.; Lee, T.H.; Nakamura, K.; Liou, Y.C.; Sun, A.; Finn, G.; Pastorino, L.; Lee, V.M.; Lu, K.P. Pin1 has opposite effects on wild-type and P301L tau stability and tauopathy. J. Clin. Investig. 2008, 118, 1877-1889.

177. Bulbarelli, A.; Lonati, E.; Cazzaniga, E.; Gregori, M.; Masserini, M. Pin1 affects Tau phosphorylation in response to A $\beta$-oligomers. Mol. Cell. Neurosci. 2009, 42, 75-80.

178. Ma, S.L.; Pastorino, L.; Zhou, X.Z.; Lu, K.P. Prolyl isomerase Pin1 promotes amyloid precursor protein (APP) turnover by inhibiting glycogen synthase kinase-3 $\beta$ (GSK3 $\beta$ ) activity: Novel mechanism for Pin1 to protect against Alzheimer disease. J. Biol. Chem. 2012, 287, 6969-6973.

179. Tamayev, R.; Zhou, D.; D'Adamio, L. The interactome of the amyloid- $\beta$ precursor protein family members is shaped by phosphorylation of their intracellular domains. Mol. Neurodegener. 2009, 4, 28.

180. Williamson, R.; Usardi, A.; Hanger, D.P.; Anderton, B.H. Membrane-bound beta-amyloid oligomers are recruited into lipid rafts by a fyn-dependent mechanism. FEBS J. 2008, 22, 1552-1559.

181. Roberson, E.D.; Halabisky, B.; Yoo, J.W.; Yao, J.; Chin, J.; Yan, F.; Wu, T.; Hamto, P.; Devidze, N.; Yu, G.Q.; et al. Amyloid-beta/Fyn-induced synaptic, network, and cognitive impairments depend on tau levels in multiple mouse models of Alzheimer's disease. J. Neurosci. 2011, 31, 700-711.

182. Hernandez, P.; Lee, G.; Sjoberg, M.; Maccioni, R.B. Tau phosphorylation by cdk5 and Fyn in response to amyloid peptide Abeta (25-35): Involvement of lipid rafts. J. Alzheimers. Dis. 2009, 16, 149-156.

183. Scales, T.M.; Derkinderen, P.; Leung, K.Y.; Byers, H.L.; Ward, M.A.; Price, C.; Bird, I.N.; Perera, T.; Kellie, S.; Williamson, R.; et al. Tyrosine phosphorylation of tau by the SRC family kinases lck and fyn. Mol. Neurodegener. 2011, 6, 12.

184. Bhaskar, K.; Hobbs, G.A.; Yen, S.H.; Lee, G. Tyrosine phosphorylation of tau accompanies disease progression in transgenic mouse models of tauopathy. Neuropathol. Appl. Neurobiol. 2010, 36, 462-477. 
185. Usardi, A.; Pooler, A.M.; Seereeram, A.; Reynolds, C.H.; Derkinderen, P.; Anderton, B.; Hanger, D.P.; Noble, W.; Williamson, R. Tyrosine phosphorylation of tau regulates its interactions with Fyn SH2 domains, but not SH3 domains, altering the cellular localization of tau. FEBS J. 2011, 278, 2927-2937.

186. Pritchard, S.M.; Dolan, P.J.; Vitkus, A.; Johnson, G.W.V. The toxicity of tau in Alzheimer disease: Turnover, targets and potential therapeutics. J. Cell. Mol. Med. 2011, 15, 1621-1635.

187. Dou, F.; Netzer, W.J.; Tanemura, K.; Li, F.; Hartl, F.U.; Takashima, A.; Gouras, G.K.; Greengard, P.; Xu, H. Chaperones increase association of tau protein with microtubules. Proc. Natl. Acad. Sci. USA 2003, 100, 721-726.

188. Miyata, Y.; Koren, J., III; Kiray, J.; Dickey, C.A.; Gestwicki, J.E. Molecular chaperones and regulation of tau quality control:strategies for drug discovery in tauopathies. Futur. Med. Chem. 2011, 3, 1523-1537.

189. Petrucelli, L.; Dickson, D.; Kehoe, K.; Taylor, J.; Snyder, H.; Grover, A.; de Lucia, M.; McGowan, E.; Lewis, J.; Prihar, G.; et al. CHIP and Hsp70 regulate tau ubiquitination, degradation and aggregation. Hum. Mol. Genet. 2004, 13, 703-714.

190. Jinwal, U.K.; O’Leary, J.C., III; Borysov, S.I.; Jones, J.R.; Li, Q.; Koren, J., III; Abisambra, J.F.; Vestal, G.D.; Lawson, L.Y.; Johnson, A.G.; et al. Hsc70 rapidly engages tau after microtubule destabilization. J. Biol. Chem. 2010, 285, 16798-16805.

191. Jinwal, U.K.; Koren, J., III; Borysov, S.I.; Schmid, A.B.; Abisambra, J.F.; Blair, L.J.; Johnson, A.G.; Jones, J.R.; Shults, C.L.; O’Leary, J.C., III; et al. The Hsp90 cochaperone, FKBP51, increases tau stability and polymerizes microtubules. J. Neurosci. 2010, 30, 591-599.

192. Tortosa, E.; Santa-Maria, I.; Moreno, F.; Lim, F.; Perez, M.; Avila, J. Binding of Hsp90 to tau promotes a conformational change and aggregation of tau protein. J. Alzheimers Dis. 2009, 17, 319-325.

193. Dickey, C.A.; Dunmore, J.; Lu, B.; Wang, J.W.; Lee, W.C.; Kamal, A.; Burrows, F.; Eckman, C.; Hutton, M.; Petrucelli, L. HSP induction mediates selective clearance of tau phosphorylated at proline-directed Ser/Thr sites but not KXGS (MARK) sites. FASEB J. 2006, 20, 753-765.

194. Dickey, C.A.; Koren, J.; Zhang, Y.J.; Xu, Y.F.; Jinwal, U.K.; Birnbaum, M.J.; Monks, B.; Sun, M.; Cheng, J.Q.; Patterson, C.; et al. Akt and CHIP coregulate tau degradation through coordinated interactions. Proc. Natl. Acad. Sci. USA 2008, 105, 3622-3627.

195. Cao, W.; Konsolaki, M. FKBP immunophilins and Alzheimer's disease: A chaperoned affair. J. Biosci. 2011, 36, 493-498.

196. Blair, L.J.; Nordhues, B.A.; Hill, S.E.; Scaglione, K.M.; O’Leary, J.C., III; Fontaine, S.N.; Breydo, L.; Zhang, B.; Li, P.; Wang, L.; et al. Accelerated neurodegeneration through chaperone-mediated oligomerization of tau. J. Clin. Investig. 2013, 123, 4158-4169.

197. Chambraud, B.; Sardin, E.; Giustiniani, J.; Dounane, O.; Schumacher, M.; Goedert, M.; Baulieu, E. A role for FKBP52 in Tau protein function. Proc. Natl. Acad. Sci. USA 2010, 107, 2658-2663.

198. Korff, A.; Liu, C.; Ginghina, C.; Shi, M.; Zhang, J. $\alpha$-Synuclein in cerebrospinal fluid of Alzheimer's disease and mild cognitive impairment. J. Alzheimers Dis. 2013, 36, 679-688. 
199. Hashiguchi, M.; Hashiguchi, T. Kinase-Kinase Interaction and Modulation of Tau Phosphorylation. Int. Rev. Cell. Mol. Biol. 2013, 300, 121-160.

200. Kawakami, F.; Suzuki, M.; Shimada, N.; Kagiya, G.; Ohta, E.; Tamura, K.; Maruyama, H.; Ichikawa, T. Stimulatory effect of $\alpha$-synuclein on the tau-phosphorylation by GSK-3 $\beta$. FEBS J. 2011, 278, 4895-4904.

201. Qureshi, H.Y.; Paudel, H.K. Parkinsonian neurotoxin 1-methyl-4phenyl-1,2,3,6tetrahydropyridine (MPTP) and $\alpha$-synuclein mutations promote Tau protein phosphorylation at $\operatorname{Ser}^{262}$ and destabilize microtubule cytoskeleton in vitro. J. Biol. Chem. 2011, 286, 5055-5068.

202. Whiteman, I.T.; Gervasio, O.L.; Cullen, K.M.; Guillemin, G.J.; Jeong, E.V.; Witting, P.K.; Antao, S.T.; Minamide, L.S.; Bamburg, J.R.; Goldsbury, C. Activated ADF/cofilin sequesters phosphorylated microtubuleassociated-protein during the assembly of Alzheimer-like neuritic cytoskeletal striations. J. Neurosci. 2009, 29, 12994.

203. Poulain, F.E.; Sobel, A. The microtubule network and neuronal morphogenesis: Dynamic and coordinated orchestration through multiple players. Mol. Cell. Neurosci. 2010, 43, 15-32.

204. Grimm-Günter, E.S.; Milbrandt, M.; Merkl, B.; Paulsson, M.; Plomann, M. PACSIN proteins bind tubulin andpromotemicrotubule assembly. Exp. Cell Res. 2008, 314, 1991-2003.

205. Liu, Y.; Lv, K.; Li, Z.; Yu, A.C.H.; Chen, J.; Teng, J. PACSIN1, a Tau-interacting protein, regulates axonal elongation and branching by facilitating microtubule instability. J. Biol. Chem. 2012, 287, 39911-39924.

206. Crowther, R.A.; Goedert, M. Abnormal tau-containing filaments in neurodegenerative diseases. J. Struct. Biol. 2000, 130, 271-279.

207. Kosik, K.S.; Shimura, H. Phosphorylated tau and the neurodegenerative foldopathies. Biochim. Biophys. Acta 2005, 1739, 298-310.

208. Avila, J.; Lucas, J.J.; Perez, M.; Hernandez, F. Role of Tau in both physiological and pathological conditions. Physiol. Rev. 2004, 84, 361-384.

209. Jeganathan, S.; Hascher, A.; Chinnathambi, S.; Biernat, J.; Mandelkow, E.M.; Mandelkow, E. Proline-directed pseudo-phosphorylation at AT8 and PHF1 epitopes induces a compaction of the paperclip folding of Tau and generates a pathological (MC-1) conformation. J. Biol. Chem. 2008, 283, 32066-32076.

210. Hyman, B.T.; Augustinack, J.C.; Ingelsson, M. Transcriptional and conformational changes of the tau molecule in Alzheimer's disease. Biochim. Biophys. Acta 2005, 1739, 150-157.

211. Delacourte, A.; Buee, L. Normal and pathological Tau proteins as factors for microtubule assembly. Int. Rev. Cytol. 1997, 171, 167-224.

212. Johnson, G.V.; Stoothoff, W.H. Tau phosphorylation in neuronal cell function and dysfunction. J. Cell Sci. 2004, 117, 5721-5729.

213. Drechsel, D.N.; Hyman, A.A.; Cobb, M.H.; Kirschner, M.W. Modulation of the dynamic instability of tubulin assembly by the microtubule-associated protein tau. Mol. Biol. Cell 1992, 3, 1141-1154.

214. Wischik, C.M.; Edwards, P.C.; Lai, R.Y.; Gertz, H.N.; Xuereb, J.H.; Paykel, E.S.; Brayne, C.; Huppert, F.A.; Mukaetova-Ladinska, E.B.; Mena, R.; et al. Quantitative analysis of tau protein in paired helical filament preparations: Implications for the role of tau protein phosphorylation in PHF assembly in Alzheimer's disease. Neurobiol. Aging 1995, 16, 409-417. 
215. Feuillette, S.; Miguel, L.; Frébourg, T.; Campion, D.; Lecourtois, M. Drosophila models of human tauopathies indicate that Tau protein toxicity in vivo is mediated by soluble cytosolic phosphorylated forms of the protein. J. Neurochem. 2010, 113, 895-903.

216. Rocher, A.B.; Crimins, J.L.; Amatrudo, J.M.; Kinson, M.S.; Todd-Brown, M.A.; Lewis, J.; Luebke, J.I. Structural and functional changes in tau mutant mice neurons are not linked to the presence of NFTs. Exp. Neurol. 2010, 223, 385-393.

217. Cowan, C.M.; Bossing, T.; Page, A.; Shepherd, D.; Mudher, A. Soluble hyper-phosphorylated tau causes microtubule breakdown and functionally compromises normal tau in vivo. Acta Neuropathol. 2010, 120, 593-604.

218. Cowan, C.M.; Mudher, A. Are tau aggregates toxic or protective in tauopathies? Front. Neurol. 2013, 13, 4-114.

219. Brunden, K.R.; Trojanowski, J.Q.; Lee, V.M. Evidence that non-fibrillar tau causes pathology linked to neurodegeneration and behavioral impairments. J. Alzheimers Dis. 2008, 14, 393-9.

220. Kayed R. Anti-tau oligomers passive vaccination for the treatment of Alzheimer disease. Hum. Vaccin. 2010, 6, 931-5.

221. Spires-Jones, T.L.; Kopeikina, K.J.; Koffie, R.M.; de Calignon, A.; Hyman, B.T. Are tangles as toxic as they look? J. Mol. Neurosci. 2011, 45, 438-44.

222. Patterson, K.R.; Ward, S.M.; Combs, B.; Voss, K.; Kanaan, N.M.; Morfini, G.; Brady, S.T.; Gamblin, T.C.; Binder, L.I. Heat shock protein 70 prevents both tau aggregation and the inhibitory effects of preexisting tau aggregates on fast axonal transport. Biochemistry 2011, 50, $10300-10310$.

223. Lasagna-Reeves, C.A.; Castillo-Carranza, D.L.; Sengupta, U.; Clos, A.L.; Jackson, G.R.; Kayed, R. Tau oligomers impair memory and induce synaptic and mitochondrial dysfunction in wild-typemice. Mol. Neurodegener. 2011, 6, 39.

224. Berger, Z.; Roder, H.; Hanna, A.; Carlson, A.; Rangachari, V.; Yue, M.; Wszolek, Z.; Ashe, K.; Knight, J.; Dickson, D.; et al. Accumulation of pathological tau species and memory loss in a conditional model of tauopathy. J. Neurosci. 2007, 27, 3650-3662.

225. Sahara, N.; Maeda, S.; Murayama, M.; Suzuki, T.; Dohmae, N.; Yen, S.H.; Takashima, A. Assembly of two distinct dimers and higher-orderoligomers from full-length tau. Eur. J. Neurosci. 2007, 25, 3020-3029.

226. Spires-Jones, T.L.; Stoothoff, W.H.; de Calignon, A.; Jones, P.B.; Hyman B.T. Tau pathophysiology in neurodegeneration: A tangled issue. Trends Neurosci. 2009, 32, 150-159.

227. Haase, C.; Stieler, J.T.; Arendt, T.; Holzer, M. Pseudophosphorylation of tau protein alters its ability for self-aggregation. J. Neurochem. 2004, 88, 1509-1520.

228. Cho, J.H.; Johnson, G.V. Primed phosphorylation of tau at Thr231 by glycogen synthase kinase 3beta (GSK3beta) plays a critical role in regulating tau's ability to bind and stabilize microtubules. J. Neurochem. 2004, 88, 349-358.

229. Sun, Q.; Gamblin, T.C. Pseudohyperphosphorylation causing AD-like changes in tau has significant effects on its polymerization. Biochemistry 2009, 48, 6002-6011.

230. Min, S.W.; Cho, S.H.; Zhou, Y.; Schroeder, S.; Haroutunian, V.; Seeley, W.W.; Huang, E.J.; Shen, Y.; Masliah, E.; Mukherjee, C.; et al. Acetylation of tau inhibits its degradation and contributes to tauopathy. Neuron 2010, 67, 953-966. 
231. Irwin, D.J.; Cohen, T.J.; Grossman, M.; Arnold, S.E.; Xie, S.X.; Lee, V.M.; Trojanowski, J.Q. Acetylated tau, a novel pathological signature in Alzheimer's disease and other tauopathies. Brain 2012, 135, 807-818.

232. Alonso, A.D.; Grundke-Iqbal, I.; Barra, H.S.; Iqbal, K. Abnormal phosphorylation of tau and the mechanism of Alzheimer neurofibrillary degeneration: Sequestration of microtubule-associated proteins 1 and 2 and the disassembly of microtubules by the abnormal tau. Proc. Natl. Acad. Sci. USA 1997, 94, 298-303.

233. Alonso, A.D.; Zaidi, T.; Novak, M.; Grundke-Iqbal, I.; Iqbal, K. Hyperphosphorylation induces self-assembly of tau into tangles of paired helical filaments/straight filaments. Proc. Natl. Acad. Sci. USA 2001, 98, 6923-6928.

234. Duan, A.R.; Goodson, H.V. Taxol-stabilized microtubules promote the formation of filaments from unmodified full-length Tau in vitro. Mol. Biol. Cell 2012, 23, 4796-4806,

235. Masliah, E.; Iimoto, D.S.; Saitoh, T.; Hansen, L.A.; Terry, R.D. Increased immunoreactivity of brain spectrin in Alzheimer disease: A marker for synapse loss? Brain Res. 1990, 531, 36-44.

236. Nelson, P.T.; Alafuzoff, I.; Bigio, E.H.; Bouras, C.; Braak, H.; Cairns, N.J.; Castellani, R.J.; Crain, B.J.; Davies, P.; del Tredici, K.; et al. Correlation of Alzheimer disease neuropathologic changes with cognitive status: A review of the literature. J. Neuropathol. Exp. Neurol. 2012, 71, 362-381.

237. Billingsley, M.L.; Kincaid, R.L. Regulated phosphorylation and dephosphorylation of tau protein: Effects on microtubule interaction, intracellular trafficking and neurodegeneration. Biochem. J. 1997, 323, 577-591.

238. Bunker, J.M.; Kamath, K.; Wilson, L.; Jordan, M.A.; Feinstein, S.C. FTDP-17 mutations compromise the ability of tau to regulate microtubule dynamics in cells. J. Biol. Chem. 2006, 281, 11856-11863.

239. Díaz-Nido, J.; Wandosell, F.; Avila, J. Glycosaminoglycans and beta-amyloid, prion and tau peptides in neurodegenerative diseases. Peptides 2002, 23, 1323-1332.

240. Stokin, G.B.; Goldstein, L.S. Axonal transport and Alzheimer's disease. Annu. Rev. Biochem. 2006, 75, 607-627.

241. Kanaan, N.M.; Pigino, G.F.; Brady, S.T.; Lazarov, O.; Binder, L.I.; Morfini, G.A. Axonal degeneration in Alzheimer's disease: When signaling abnormalities meet the axonal transport system. Exp. Neurol. 2013, 246, 44-53.

242. Chevalier-Larsen, E.; Holzbaur, E.L. Axonal transport and neurodegenerative disease. Biochim. Biophys. Acta 2006, 1762, 1094-1108.

243. Lau, C.G.; Zukin, R.S. NMDA receptor trafficking in synaptic plasticity and neuropsychiatric disorders. Nat. Rev. Neurosci. 2007, 8, 413-426.

244. Van Spronsen, M.; Hoogenraad, C.C. Synapse pathology in psychiatric and neurologic disease. Curr. Neurol. Neurosci. Rep. 2010, 10, 207-214.

245. Kapitein, L.C.; Hoogenraad, C.C. Which way to go? Cytoskeletal organization and polarized transport in neurons. Mol. Cell. Neurosci. 2011, 46, 9-20.

246. Hirokawa, N.; Noda, Y. Intracellular transport and kinesin superfamily proteins, KIFs: Structure, function, and dynamics. Physiol. Rev. 2008, 88, 1089-1118. 
247. Falzone, T.L.; Gunawardena, S.; McCleary, D.; Reis, G.F.; Goldstein, L.S. Kinesin-1 transport reductions enhance human tau hyperphosphorylation, aggregation and neurodegeneration in animal models of tauopathies. Hum. Mol. Genet. 2010, 19, 4399-4408.

248. Terada, S.; Kinjo, M.; Aihara, M.; Takei, Y.; Hirokawa, N. Kinesin-1/Hsc70-dependent mechanism of slow axonal transport and its relation to fast axonal transport. EMBO J. 2010, 29, 843-854.

249. Gunawardena, S.; Goldstein, L.S. Cargo-carrying motor vehicles on the neuronal highway: Transport pathways and neurodegenerative disease. J. Neurobiol. 2004, 58, 258-271.

250. Perlson, E.; Maday, S.; Fu, M.M.; Moughamian, A.J.; Holzbaur, E.L. Retrograde axonal transport: Pathways to cell death? Trends Neurosci. 2010, 33, 335-344.

251. Bendiske, J.; Caba, E.; Brown, Q.B.; Bahr, B.A. Intracellular deposition, microtubule destabilization, and transport failure: An 'early' pathogenic cascade leading to synaptic decline. J. Neuropathol. Exp. Neurol. 2002, 61, 640-650.

252. Kamal, A.; Stokin, G.B.; Yang, Z.; Xia, C.H.; Goldstein, L.S. Axonal transport of amyloid precursor protein is mediated by direct binding to the kinesin light chain subunit of kinesin-I. Neuron 2000, 28, 449-459.

253. Morel, M.; Héraud, C.; Nicaise, C.; Suain, V.; Brion, J.P. Levels of kinesin light chain and dynein intermediate chain are reduced in the frontal cortex in Alzheimer's disease: Implications for axoplasmic transport. Acta Neuropathol. 2012, 123, 71-84.

254. Hashimoto, Y.; Tsuji, O.; Niikura, T.; Yamagishi, Y.; Ishizaka, M.; Kawasumi, M.; Chiba, T.; Kanekura, K.; Yamada, M.; Tsukamoto, E.; et al. Involvement of c-Jun $N$-terminal kinase in amyloid precursor protein-mediated neuronal cell death. J. Neurochem. 2003, 84, 864-877.

255. Futerman, A.H.; Banker, G.A. The economics of neurite outgrowth-The addition of new membrane to growing axons. Trends Neurosci. 1996, 19, 144-149.

256. Stamer, K.; Vogel, R.; Thies, E.; Mandelkow, E.; Mandelkow, E.M. Tau blocks traffic of organelles, neurofilaments, and APP vesicles in neurons and enhances oxidative stress. J. Cell Biol. 2002, 18, 1051-1063.

257. Mandelkow, E.M.; Stamer, K.; Vogel, R.; Thies, E.; Mandelkow, E. Clogging of axons by tau, inhibition of axonal traffic and starvation of synapses. Neurobiol. Aging 2003, 24, 1079-1085.

258. Calissano, P.; Matrone, C.; Amadoro, G. Nerve growth factor as a paradigm of neurotrophins related to Alzheimer's disease. Dev. Neurobiol. 2010, 70, 372-383.

259. Thies, E.; Mandelkow, E.M. Missorting of tau in neurons causes degeneration of synapses that can be rescued by the kinase MARK2/Par-1. J. Neurosci. 2007 27, 2896-2907.

260. Tatebayashi, Y.; Haque, N.; Tung, Y.C.; Iqbal, K.; Grundke-Iqbal, I. Role of tau phosphorylation by glycogen synthase kinase-3beta in the regulation of organelle transport. J. Cell Sci. 2004, 117, 1653-1663.

261. Watson, F.L.; Heerssen, H.M.; Moheban, D.B.; Lin, M.Z.; Sauvageot, C.M.; Bhattacharyya, A.; Pomeroy, S.L.; Segal, R.A. Rapid nuclear responses to target-derived neurotrophins require retrograde transport of ligand-receptor complex. J. Neurosci. 1999, 15, 7889-7900.

262. Sandow, S.L.; Heydon, K.; Weible, M.W., II; Reynolds, A.J.; Bartlett, S.E.; Hendry, I.A. Signaling organelle for retrograde axonal transport of internalized neurotrophins from the nerve terminal. Immunol. Cell Biol. 2000, 78, 430-435. 
263. Bhattacharyya, A.; Watson, F.L.; Pomeroy, S.L.; Zhang, Y.Z.; Stiles, C.D.; Segal, R.A. High-resolution imaging demonstrates dynein-based vesicular transport of activated Trk receptors. J. Neurobiol. 2002, 51, 302-312.

264. Heerssen, H.M.; Pazyra, M.F.; Segal, R.A. Dynein motors transport activated Trks to promote survival of target-dependent neurons. Nat. Neurosci. 2004, 7, 596-604.

265. Yano, H.; Lee, F.S.; Kong, H.; Chuang, J.; Arevalo, J.; Perez, P.; Sung, C.; Chao, M.V. Association of Trk neurotrophin receptors with components of the cytoplasmic dynein motor. J. Neurosci. 2001, 21, RC125.

266. Yano, H.; Chao, M.V. Mechanisms of neurotrophin receptor vesicular transport. J. Neurobiol. 2004, 58, 244-257.

267. Riccio, A.; Pierchal, B.A.; Ciarallo, C.L.; Ginty, D.D. A NGF-TrkA-mediated retrograde signal to transcription factor CREB in sympathetic neurons. Science 1997, 277, 1097-1100.

268. Yano, H.; Chao, M.V. Biochemical characterization of intracellular membranes bearing Trk neurotrophin receptors. Neurochem. Res. 2005, 30, 767-777.

269. Wu, C.; Ramirez, A.; Cui, B.; Ding, J.; Delcroix, J.D.; Valletta, J.S.; Liu, J.J.; Yang, Y.; Chu, S.; Mobley, W.C. A functional dynein-microtubule network is required for NGF signaling through the Rap1/MAPK pathway. Traffic 2007, 8, 1503-1520.

270. Salehi, A.; Delcroix, J.D.; Swaab, D.F. Alzheimer's disease and NGF signaling. J. Neural Transm. 2004, 111, 323-345.

271. Schindowski, K.; Belarbi, K.; Buée, L. Neurotrophic factors in Alzheimer's disease: Role of axonal transport. Genes Brain Behav. 2008, 1, 43-56.

272. Lazarov, O.; Morfini, G.A.; Pigino, G.; Gadadhar, A.; Chen, X.; Robinson, J.; Ho, H.; Brady, S.T.; Sisodia, S.S. Impairments in fast axonal transport and motor neuron deficits in transgenic mice expressing familial Alzheimer's disease-linked mutant presenilin 1. J. Neurosci. 2007, 27, 7011-7020.

273. Corsetti, V.; Amadoro, G.; Gentile, A.; Capsoni, S.; Ciotti, M.T.; Cencioni, M.T.; Atlante, A.; Canu, N.; Rohn, T.T.; Cattaneo, A.; et al. Identification of a caspase-derived $N$-terminal tau fragment in cellular and animal Alzheimer's disease models. Mol. Cell. Neurosci. 2008, 38, 381-392.

274. Magnani, E.; Fan, J.; Gasparini, L.; Golding, M.; Williams, M.; Schiavo, G.; Goedert, M.; Amos, L.A.; Spillantini, M.G. Interaction of tau protein with the dynactin complex. EMBO J. 2007, 31, 4546-4554.

275. Matrone, C.; Ciotti, M.T.; Mercanti, D.; Marolda, R.; Calissano, P. NGF and BDNF signaling control amyloidogenic route and Ab production in hippocampal neurons. Proc. Natl. Acad. Sci. USA 2008, 105, 13139-13144.

(C) 2014 by the authors; licensee MDPI, Basel, Switzerland. This article is an open access article distributed under the terms and conditions of the Creative Commons Attribution license (http://creativecommons.org/licenses/by/3.0/). 